\title{
Sequenced Combinations of Cisplatin and Selected Phytochemicals towards Overcoming Drug Resistance in Ovarian Tumour Models
}

\author{
Safiah Ibrahim Althurwi ${ }^{1}$, Jun Q. Yu ${ }^{1}$, Philip Beale ${ }^{2}$ and Fazlul Huq ${ }^{3, * \mathbb{B}}$ \\ 1 School of Medical Sciences, University of Sydney, Sydney, NSW 2006, Australia; \\ sssafy2008@hotmail.com (S.I.A.); jun.yu@sydney.edu.au (J.Q.Y.) \\ 2 Department of Medical Oncology, Concord Repatriation General Hospital, Concord, NSW 2137, Australia; \\ Philip.beale@health.nsw.gov.au \\ 3 Eman Research Ltd., Canberra, ACT 2609, Australia \\ * Correspondence: fazlul.huq@bigpond.com; Tel.: +61-411235462
}

Received: 28 August 2020; Accepted: 9 October 2020; Published: 12 October 2020

\begin{abstract}
In the present study, cisplatin, artemisinin, and oleanolic acid were evaluated alone, and in combination, on human ovarian A2780, A2780 ZD0473R, and A2780 cisR cancer cell lines, with the aim of overcoming cisplatin resistance and side effects. Cytotoxicity was assessed by MTT reduction assay. Combination index (CI) values were used as a measure of combined drug effect. MALDI TOF/TOF MS/MS and 2-DE gel electrophoresis were used to identify protein biomarkers in ovarian cancer and to evaluate combination effects. Synergism from combinations was dependent on concentration and sequence of administration. Generally, bolus was most synergistic. Moreover, 49 proteins differently expressed by $2 \geq$ fold were: CYPA, EIF5A1, Op18, p18, LDHB, P4HB, HSP7C, GRP94, ERp57, mortalin, IMMT, CLIC1, NM23, PSA3,1433Z, and HSP90B were down-regulated, whereas hnRNPA1, hnRNPA2/B1, EF2, GOT1, EF1A1, VIME, BIP, ATP5H, APG2, VINC, KPYM, RAN, PSA7, TPI, PGK1, ACTG and VDAC1 were up-regulated, while TCPA, TCPH, TCPB, PRDX6, EF1G, ATPA, ENOA, PRDX1, MCM7, GBLP, PSAT, Hop, EFTU, PGAM1, SERA and CAH2 were not-expressed in A2780 cisR cells. The proteins were found to play critical roles in cell cycle regulation, metabolism, and biosynthetic processes and drug resistance and detoxification. Results indicate that appropriately sequenced combinations of cisplatin with artemisinin (ART) and oleanolic acid (OA) may provide a means to reduce side effects and circumvent platinum resistance.
\end{abstract}

Keywords: ovarian cancer; drug resistance; apoptosis; proteomics; combination; cytotoxicity; artemisinin; oleanolic acid; platinum drugs; cisplatin

\section{Introduction}

Ovarian cancer is one of the major causes of death in gynaecologic cancers [1] marked with absence of reliable screening methods and distinctive symptoms [2,3]. Although widely used, efficacy of platinum drugs, cisplatin [1], oxaliplatin, and carboplatin, is limited due to acquired resistance and adverse side effects. Combination treatments [4] with tumour active plant based compounds that have atypical mechanisms of action, and minor or no side effects, can provide a means to overcome drug resistance [5]. Resistance to platinum-based drugs [6,7] is related to four major mechanisms, which are: (1) increased detoxification and degradation (such as by glutathione); (2) reduced drug accumulation (due to increased efflux and/or reduced influx); (3) increased repair of the Pt-DNA adducts; or (4) enhanced tolerance of the damaged DNA [8].

Oleanolic acid (OA) is a natural pentacyclic triterpenoid (Figure 1) [9], predominantly found in olive oil [10], which exhibits antioxidant, anti-inflammatory, anticancer, and hepatoprotective activities [9]. 
OA is reported to inhibit metastasis, angiogenesis, and invasion in different cancers [10], while it induces programmed cell death in different cancer cell lines, such as osteosarcoma, liver, gastric, breast, prostate, pancreatic, colorectal, and bladder cancer cells [10] via enhancement of p38 MAPK, ASK1, ROS, and inhibition of signalling pathways, such as S6K, PI3K, mTOR, Akt, and NF-kB in time- and concentration-dependent fashion [10]. However, it shows pro-apoptotic and anti-proliferative effects through down-regulation of survivin, $\mathrm{Bcl}-\mathrm{xL}, \mathrm{Bcl}-2$, and other anti-apoptosis proteins accompanied with modulation of MRP1 activity [10]. Artemisinin (ART), is obtained from (Sweet wormwood, Artemisia annua L), (Figure 1) [11]. It inhibits metastasis, invasion, and angiogenesis, while it induces apoptosis and cell cycle arrest [11]. Artemisinin and its derivatives also exhibit anti-malarial, and anti-inflammatory activities [11] through modulation of molecular pathways, such as tyrosine kinases, STAT-1/3/5, NF-kB, MAPKs, PI3K/Akt Sp1, Toll-like receptors, Nrf2/ARE phospholipase, p53, and MDM2 oncogene [11]. Another study reported that artemisinins increase E-cadherin, Bax and reduce MMPs, BCL-2, HIF-1 $\alpha$, VEGF, CDKs, and cyclins [12]. It has been suggested that ART induces DNA damage and apoptosis by producing free radicals that result from the reaction of its endoperoxide moiety with intracellular free iron [12]. However, the effect is influenced by cancer cell phenotype and the origin of tissue [13]. A growing body of evidence suggests that the combination treatment with plant-based anticancer agents and common cancer drugs can improve effectiveness of chemotherapeutic agents through regulation of pathways, including the ones regulated by COX-2, nuclear factor-KB, and Akt (which are also associated with drug resistance) [5]. Thus, it is thought that artemisinin and oleanolic acid would act synergistically with cisplatin by regulating various pathways and repressing different mechanisms involved in cancer initiation, metastasis, invasion, and angiogenesis.

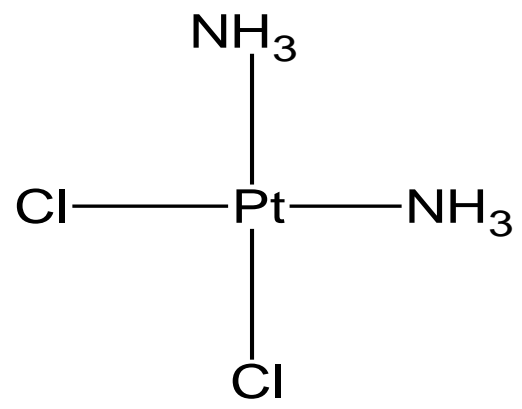

Cisplatin (CS)

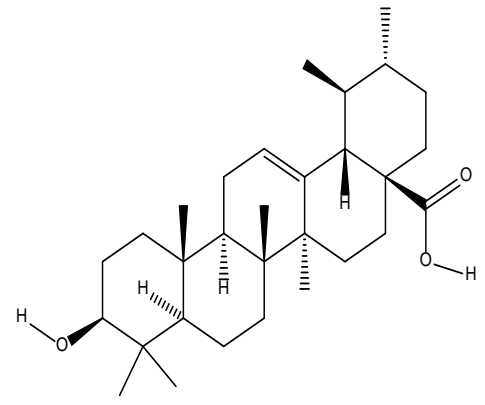

Oleanolic acid (OA)

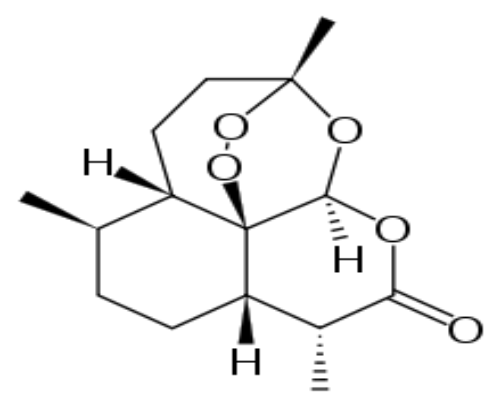

Artemisinin (ART)

Figure 1. Chemical structure of cisplatin, oleanolic acid, and artemisinin.

The current study aimed to examine efficacy from binary combinations of artemisinin and oleanolic acid with cisplatin in A2780, A2780 cisR (A2780 made resistant to cisplatin), and A2780 ${ }^{\mathrm{ZD} 0473 \mathrm{R}}$ (A2780 made resistant to platinum compound ZD0473) human ovarian cancer cell lines. Selected combinations were chosen to determine their effect on cellular platinum accumulation and $\mathrm{Pt}$-DNA binding levels, changes in protein expression (using 2-DE gel electrophoresis). Finally, MALDI -TOF-TOF MS/MS was used to identify the proteins. Various studies relate to drug efficacy alone and in combination, and the mechanisms of action.

\section{Results}

\subsection{Growth-Inhibitory Effect of Single Drugs}

The concentration of cisplatin (CS), OA, and ART that caused 50\% growth inhibition in A2780, $\mathrm{A} 2780^{\mathrm{cisR}}$, and $\mathrm{A} 2780^{\mathrm{ZD} 0473 \mathrm{R}}$ cell lines, was identified as $\mathrm{IC}_{50}$ values. The data revealed (in Table 1) that the highest resistant factor (RF) value was applied to CS, whereas the lowest was produced by OA. Among the two phytochemicals in the A2780 cell line, ART was the more active, whereas, in the A2780 $0^{\text {cisR }}$ and $\mathrm{A} 2780^{\mathrm{ZD} 0473 \mathrm{R}}$ cell lines, OA was the more active compound. 
Table 1. $\mathrm{IC}_{50}$ values of cisplatin (CS), artemisinin (ART), and oleanolic acid (OA) as applied to the human ovarian cancer cell lines, A2780 A2780 cisR, and A2780 ZD0473R cell lines based on, at least, triplicate measurements, with the period of incubation being $72 \mathrm{~h}$.

\begin{tabular}{cccccc}
\hline \multicolumn{7}{c}{ IC $_{\mathbf{5 0}}(\boldsymbol{\mu} \mathbf{M})$ and RF Values } \\
\hline Drug & $\mathbf{A 2 7 8 0}$ & $\mathbf{A 2 7 8 0}^{\text {cisR }}$ & ${ }^{*} \mathbf{R F}$ & A2780 $^{\text {ZD0473R }}$ & RF \\
\hline CS & $0.66 \pm 0.08$ & $6.44 \pm 0.11$ & 9.75 .63 & $8.37 \pm 0.06$ & 12.6 \\
ART & $16.78 \pm 0.06$ & $26.8 \pm 0.13$ & 1.60 & $36.36 \pm 0.09$ & 2.16 \\
OA & $34.0 \pm 0.31$ & $26.15 \pm 0.28$ & 0.76 & $10.85 \pm 0.05$ & 0.3 \\
\hline \multicolumn{7}{c}{}
\end{tabular}

${ }^{*}$ RF: resistant factors.

\subsection{Combination Studies}

Combination indices (CIs) were calculated using the formula developed by Chou and Talalay to determine whether the combined drug action was antagonistic, synergistic, or additive. A CI value $<1$ means a synergistic effect, equal to one means an additive effect, and $>1$ means an antagonistic effect of the combined drugs [14] $\mathrm{ED}_{50}, \mathrm{ED}_{75}$, and $\mathrm{ED}_{90}$ standing for concentrations applying respectively to $50 \%, 75 \%$, and $90 \%$ growth inhibition, were determined for all combinations. In essence, $\mathrm{ED}_{50}, \mathrm{ED}_{75}$, and $\mathrm{ED}_{90}$ are equivalent to $\mathrm{IC}_{50}, \mathrm{IC}_{75}$, and $\mathrm{IC}_{90} . \mathrm{D}_{\mathrm{m}}$ is the median effect dose and $\mathrm{m}$ is the exponent defining shape of the dose response curve. All drugs in combination were added using the following three modes of administration: $(0 / 0 \mathrm{~h}, 0 / 4 \mathrm{~h}$, and $4 / 0 \mathrm{~h})$ to the selected cell lines where $0 / 0 \mathrm{~h}, 0 / 4 \mathrm{~h}$, and $4 / 0 \mathrm{~h}$ respectively mean both drugs are added at the same time; cisplatin was added first, followed by phytochemical four hours later, and phytochemical was added first followed by cisplatin four hours later. In regards to the A2780 cell line, the data show that CS and ART (Table 2 and Figure 2), using $0 / 0 \mathrm{~h}$ produced the highest synergistic effect while the lowest synergistic outcome was produced from ( $0 / 4 \mathrm{~h}$ ). In contrast, CS and OA (Table 3 and Figure 2), using $0 / 4 \mathrm{~h}$ showed the highest synergistic outcome and the least was produced from $4 / 0 \mathrm{~h}$. On the other hand, in relation to the A2780 ${ }^{\text {cisR }}$ cell line, CS and ART (Table 3 and Figure 2) using 0/0 h exhibited the highest synergistic outcome, and the lowest resulted from $4 / 0 \mathrm{~h}$ combination. Likewise, CS and OA (Table 3 and Figure 2) using 0/0 h produced the highest synergistic outcome, and the lowest resulted from the 4/0 h combination. Moreover, regarding the A2780 ZD473R cell line, CS and ART in combination (Table 4 and Figure 2), using 0/0 h, exhibited the highest synergistic outcome. Likewise, CS and OA in combination (Table 4 and Figure 2), using 0/0 h, resulted in the highest synergistic outcome. The results are discussed fully in the next section.

Table 2. Combination index (CI) values of CS with OA and ART in the A2780 cell line, where drugs were added in equipotent ratios based on $\mathrm{IC}_{50}$ values.

\begin{tabular}{|c|c|c|c|c|c|c|c|c|}
\hline \multicolumn{9}{|c|}{ CI Value at } \\
\hline Drug & Sequence (h) & Molar Ratio & $\mathrm{ED}_{50}$ & $\mathrm{ED}_{75}$ & $\mathrm{ED}_{90}$ & $D_{m}$ & m & $\mathbf{r}$ \\
\hline CS & & & N/A & N/A & N/A & 1.16 & 0.88 & 0.99 \\
\hline $\mathrm{OA}$ & & & N/A & N/A & N/A & 37.19 & 0.64 & 1.00 \\
\hline $\mathrm{CS}+\mathrm{OA}$ & $0 / 0$ & $1: 51.52$ & 0.72 & 0.50 & 0.37 & 0.53 & 1.06 & 0.99 \\
\hline $\mathrm{CS}+\mathrm{OA}$ & $0 / 4$ & & 0.68 & 0.59 & 0.54 & 0.49 & 0.86 & 0.97 \\
\hline $\mathrm{CS}+\mathrm{OA}$ & $4 / 0$ & & 0.92 & 1.07 & 1.28 & 0.69 & 0.72 & 0.98 \\
\hline ART & & & $\mathrm{N} / \mathrm{A}$ & N/A & N/A & 26.5 & 0.55 & 0.99 \\
\hline $\mathrm{CS}+\mathrm{ART}$ & $0 / 0$ & 1:25.42 & 0.74 & 0.55 & 0.47 & 0.40 & 0.85 & 1.00 \\
\hline $\mathrm{CS}+\mathrm{ART}$ & $0 / 4$ & & 0.86 & 1.05 & 1.46 & 0.47 & 0.62 & 0.99 \\
\hline $\mathrm{CS}+\mathrm{ART}$ & $4 / 0$ & & 0.77 & 0.55 & 0.60 & 0.32 & 0.72 & 0.99 \\
\hline
\end{tabular}

Dm: medium effect dose; $\mathrm{m}$ : exponent defining shape of the dose effect curve; r: reliability coefficient. 
Table 3. CI values of CS with OA and ART in the A2780 cisR cell line where drugs were added in equipotent ratios based on $\mathrm{IC}_{50}$ values.

\begin{tabular}{ccccccccc}
\hline & & \multicolumn{7}{c}{ CI Values at } \\
\hline Drug & Sequence (h) & Molar Ratio & ED $_{\mathbf{5 0}}$ & ED $_{\mathbf{7 5}}$ & ED $_{\mathbf{9 0}}$ & Dm & $\mathbf{m}$ & $\mathbf{r}$ \\
\hline CS & & & N/A & N/A & N/A & 8.03 & 0.63 & 0.99 \\
OA & & & N/A & N/A & N/A & 56.44 & 0.40 & 1.00 \\
CS + OA & $0 / 0$ & $1: 4.05$ & 0.57 & 0.49 & 0.50 & 2.88 & 0.61 & 1.00 \\
CS + OA & $0 / 4$ & & 0.63 & 0.42 & 0.32 & 3.15 & 0.72 & 1.00 \\
CS + OA & $4 / 0$ & & 0.77 & 0.53 & 0.43 & 3.85 & 0.70 & 0.99 \\
ART & & & N/A & N/A & N/A & 77.82 & 0.49 & 1.00 \\
CS + ART & $0 / 0$ & $1: 4.16$ & 0.54 & 0.88 & 1.51 & 2.98 & 0.48 & 1.00 \\
CS + ART & $0 / 4$ & & 0.75 & 0.67 & 0.64 & 4.17 & 0.65 & 1.00 \\
CS + ART & $4 / 0$ & & 0.87 & 0.80 & 0.78 & 4.82 & 0.64 & 1.00 \\
\hline
\end{tabular}

$\mathrm{D}_{\mathrm{m}}$ : medium effect dose; $\mathrm{m}$ : exponent defining shape of the dose effect curve; r: reliability coefficient.

Table 4. CI values of CS with OA and ART in the A2780 ZD0473R cell line where drugs were added in equipotent ratios based on $\mathrm{IC}_{50}$ values.

\begin{tabular}{ccccccccc}
\hline & & \multicolumn{7}{c}{ CI Values at } \\
\hline Drug & Sequence (h) & Molar Ratio & ED $_{\mathbf{5 0}}$ & ED $_{\mathbf{7 5}}$ & ED $_{\mathbf{9 0}}$ & $\mathbf{D}_{\mathbf{m}}$ & $\mathbf{m}$ & $\mathbf{r}$ \\
\hline CS & & & N/A & N/A & N/A & 11.35 & 0.83 & 0.98 \\
OA & & N/A & N/A & N/A & 29.43 & 0.43 & 0.96 \\
CS + OA & $0 / 0$ & $1: 1.3$ & 0.58 & 0.61 & 0.86 & 3.55 & 0.61 & 0.99 \\
CS + OA & $0 / 4$ & & 0.81 & 0.56 & 0.52 & 5.00 & 0.80 & 0.99 \\
CS + OA & $4 / 0$ & & 0.80 & 0.71 & 0.74 & 5.53 & 0.73 & 0.99 \\
ART & & & N/A & N/A & N/A & 17.19 & 0.57 & 0.99 \\
CS + ART & $0 / 0$ & $1: 4.35$ & 0.71 & 0.80 & 0.95 & 1.46 & 0.56 & 1.00 \\
CS + ART & $0 / 4$ & & 0.82 & 0.91 & 1.36 & 1.71 & 0.53 & 0.99 \\
CS + ART & $4 / 0$ & & 0.82 & 0.85 & 1.09 & 1.89 & 0.58 & 1.00 \\
\hline
\end{tabular}

$\mathrm{D}_{\mathrm{m}}$ : medium effect dose, $\mathrm{m}$ : exponent defining shape of the dose effect curve, r: reliability coefficient.

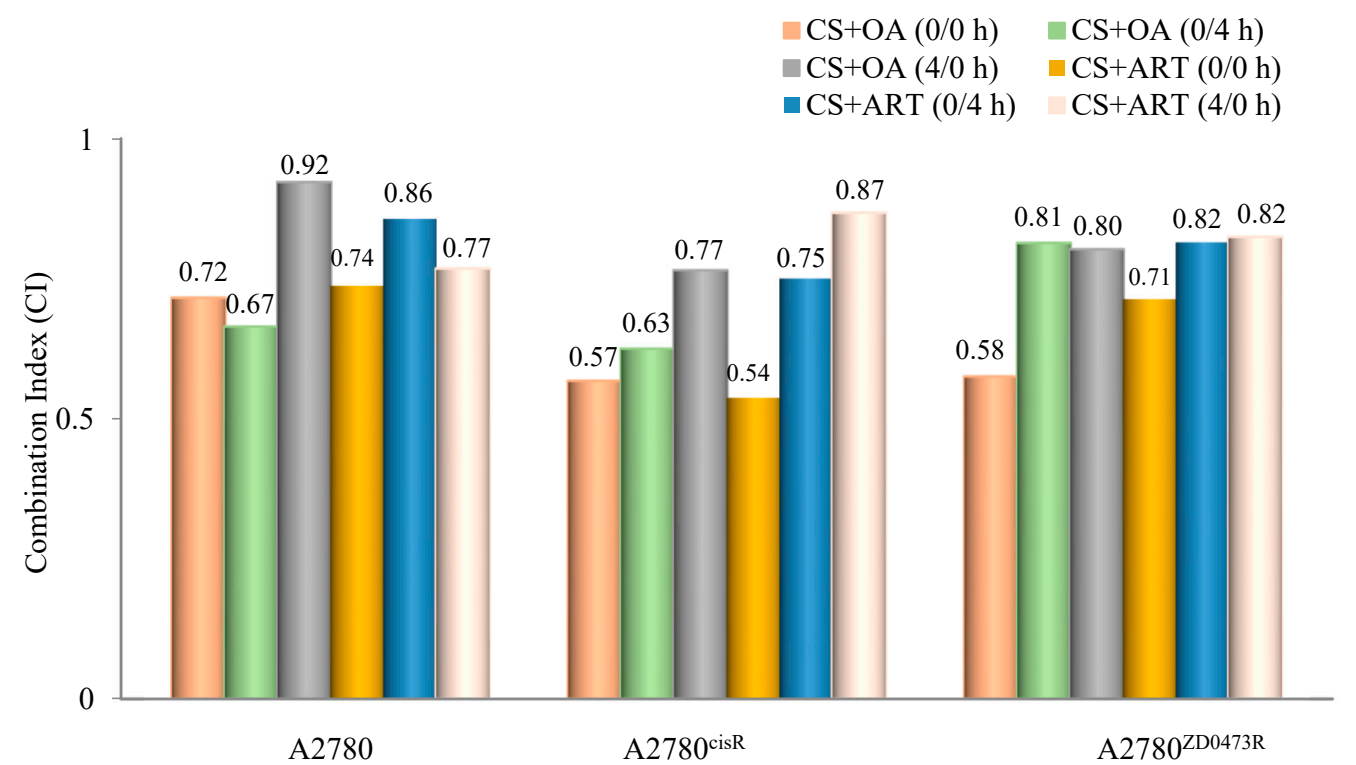

Figure 2. Graphical representation of combination indices (CI) applying to binary combinations of CS with OA and ART at ED50 (where drugs were added in equipotent ratios based on $\mathrm{IC}_{50}$ values). 


\subsection{Cellular Accumulation of Platinum and Platinum-DNA Binding Level}

\subsubsection{Cellular Accumulation of Platinum}

The data (Table 5 and Figure 3) show that platinum accumulations from the combinations of CS with ART or OA were always greater than those from CS alone in both the cell lines (A2780 and $\mathrm{A} 2780^{\mathrm{cisR}}$ ), indicating that the presence of ART and OA have served either to increase the uptake or decrease the efflux or both.

Table 5. Platinum accumulation level of CS alone and in combination with ART and OA.

\begin{tabular}{|c|c|c|c|c|}
\hline \multirow[b]{3}{*}{ DRUG } & \multicolumn{4}{|c|}{ * Platinum Accumulation } \\
\hline & \multicolumn{2}{|c|}{ A2780 } & \multicolumn{2}{|c|}{ A2780 cisR } \\
\hline & Value & Fold Change & Value & Fold Change \\
\hline CS & $0.15 \pm 0.01$ & - & $0.27 \pm 0.02$ & - \\
\hline $\mathrm{CS}+\operatorname{ART}(0 / 0 \mathrm{~h})$ & $0.65 \pm 0.04$ & 4.33 & $2.29 \pm 0.20$ & 8.48 \\
\hline $\mathrm{CS}+\mathrm{ART}(0 / 4 \mathrm{~h})$ & $0.91 \pm 0.06$ & 6.06 & $0.75 \pm 0.04$ & 2.77 \\
\hline $\mathrm{CS}+\operatorname{ART}(4 / 0 \mathrm{~h})$ & $0.22 \pm 0.02$ & 1.46 & $1.22 \pm 0.09$ & 4.51 \\
\hline $\mathrm{CS}+\mathrm{OA}(0 / 0 \mathrm{~h})$ & $2.22 \pm 0.08$ & 14.8 & $0.91 \pm 0.08$ & 3.33 \\
\hline $\mathrm{CS}+\mathrm{OA}(0 / 4 \mathrm{~h})$ & $0.27 \pm 0.01$ & 1.8 & $0.50 \pm 0.02$ & 1.85 \\
\hline $\mathrm{CS}+\mathrm{OA}(4 / 0 \mathrm{~h})$ & $0.22 \pm 0.01$ & 1.46 & $1.14 \pm 0.11$ & 4.22 \\
\hline
\end{tabular}

${ }^{*}$ Expressed as: nmol Pt per $5 \times 10^{6}$ cells.

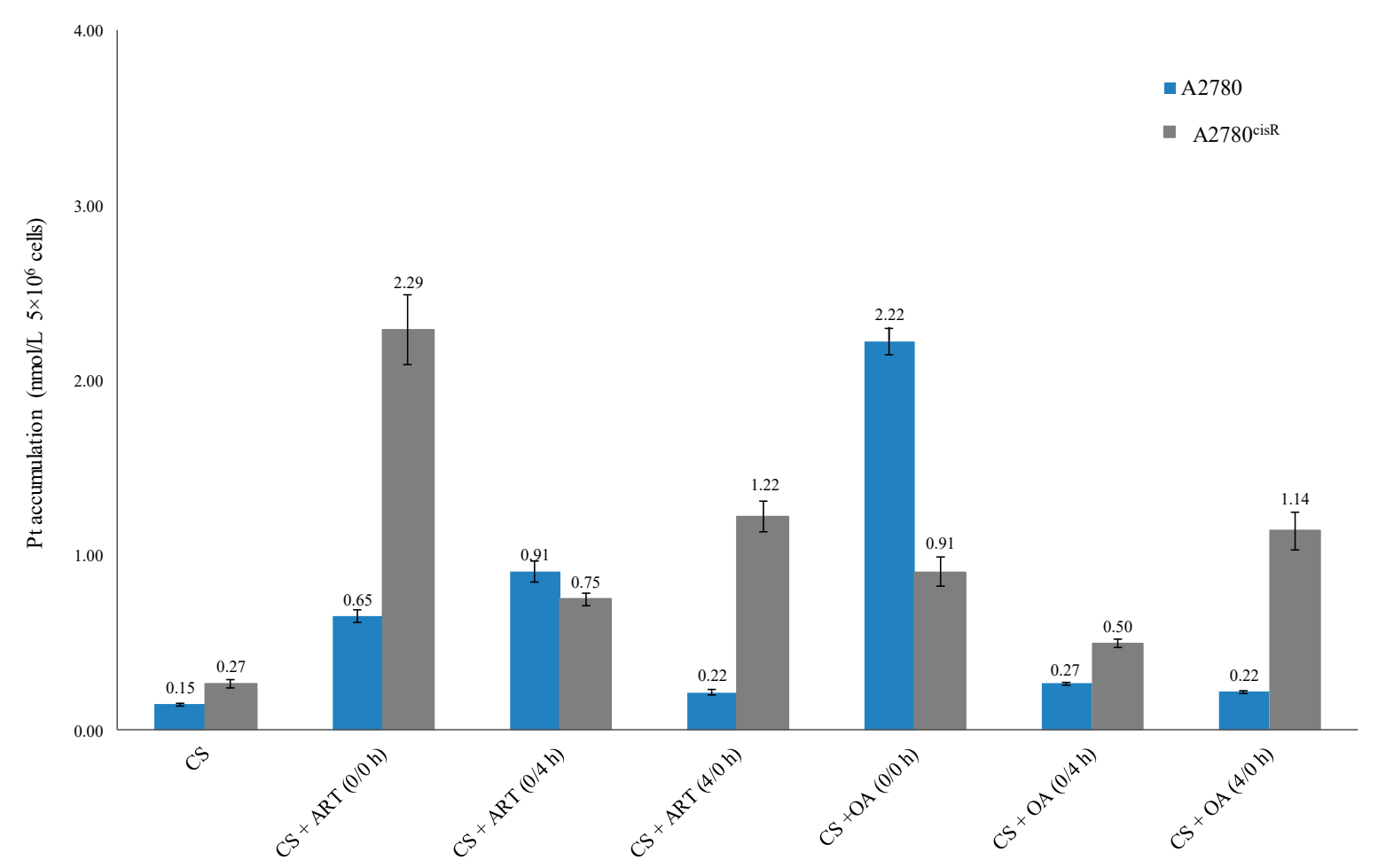

Figure 3. Platinum accumulation level from CS alone and in combination with ART and OA.

\subsubsection{Platinum-DNA Binding Level}

The data reveal that the platinum-DNA binding levels resulting from the combination of CS with ART or OA (Table 6 and Figure 4) in A2780 were not always higher than those from CS alone, indicating that a positive correlation between increased levels of CS-binding and synergistic outcomes is not always found. For example, the level of CS-DNA binding from the combination of CS with OA using 0/4 $\mathrm{h}$ was less than that of CS alone. Moreover, in A2780, CS-DNA binding level was 
sequence-dependent, but not synergistic in outcome. As the level of CS-DNA binding resulted from combinations of CS with ART using 0/0 h was lowest, whereas combination index showed that $0 / 0 \mathrm{~h}$ sequence was the most synergistic sequence. On the contrary, in the A2780 ${ }^{\mathrm{ciR}}$ cell line, platinum-DNA binding level from combination treatments was always higher than those from CS alone, suggesting the presence of such a correlation. Moreover, the observed increase in CS-binding levels in the A2780 $0^{\mathrm{ciR}}$ cell line from combination with ART and OA are consistent with the increase in CS-accumulation levels due to the treatments.

Table 6. Platinum-DNA-binding levels of CS alone and in combinations with ART and OA.

\begin{tabular}{ccccc}
\hline & \multicolumn{4}{c}{ * Platinum-DNA Binding Level } \\
\cline { 2 - 5 } & \multicolumn{2}{c}{ A2780 } & \multicolumn{2}{c}{ A2780 ${ }^{\text {cisR }}$} \\
\hline DRUG & Value & Fold Change & Value & Fold Change \\
\hline CS & $6.08 \pm 0.57$ & - & $3.66 \pm 0.49$ & - \\
CS + ART (0/0 h) & $9.24 \pm 0.64$ & 1.52 & $3.70 \pm 0.33$ & 1.01 \\
CS + ART (0/4 h) & $8.26 \pm 0.78$ & 1.36 & $8.67 \pm 0.59$ & 2.37 \\
CS + ART (4/0 h) & $3.22 \pm 0.49$ & 0.53 & $4.60 \pm 0.11$ & 1.26 \\
CS + OA (0/0 h) & $4.13 \pm 0.28$ & 0.68 & $5.12 \pm 0.43$ & 1.40 \\
CS + OA (0/4 h) & $1.66 \pm 0.11$ & 0.27 & $4.43 \pm 0.29$ & 1.21 \\
CS + OA (4/0 h) & $4.71 \pm 0.36$ & 0.77 & $7.85 \pm 0.73$ & 2.14 \\
\hline
\end{tabular}

* Expressed as: nmol Pt per mg of DNA.

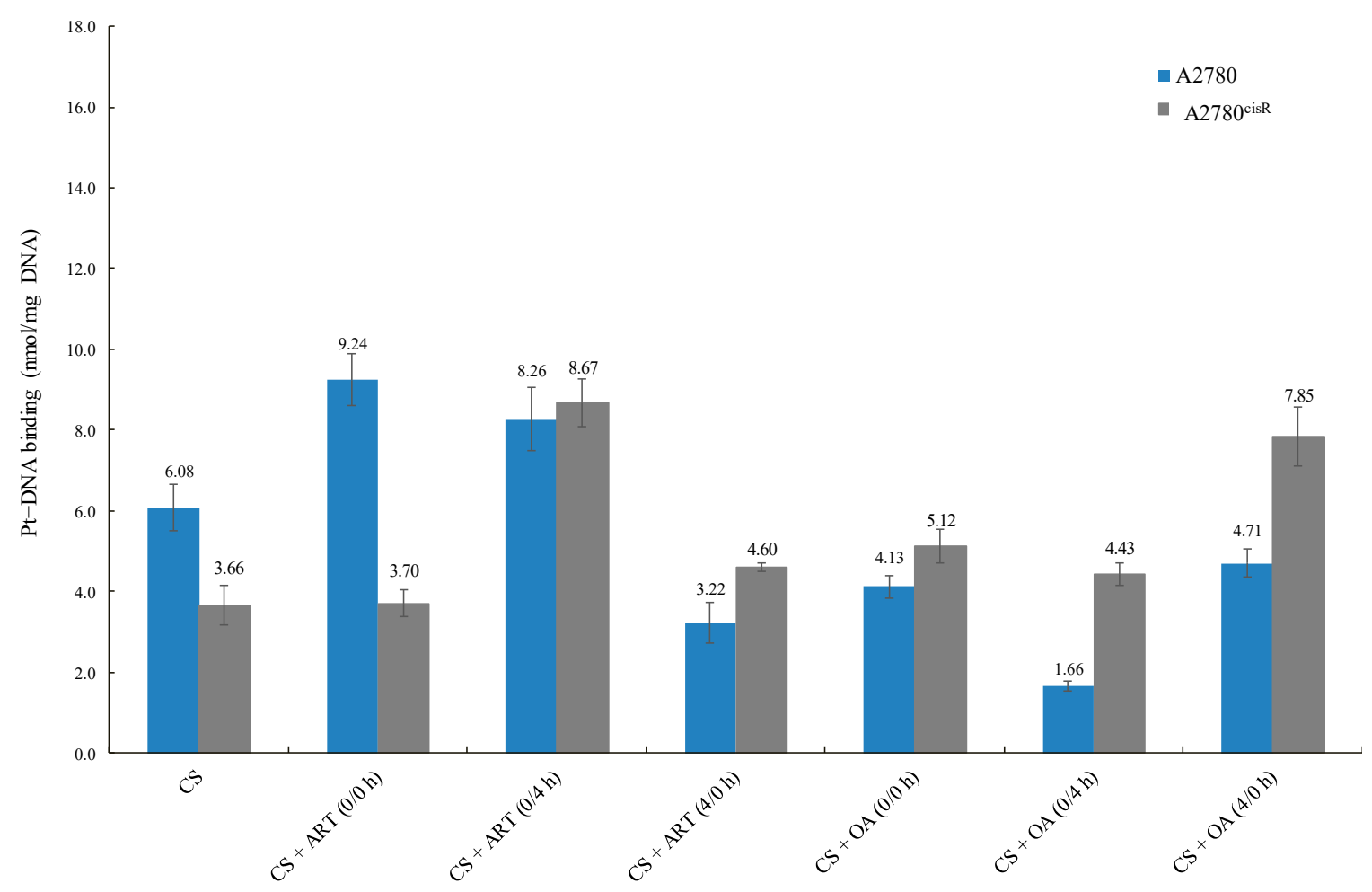

Figure 4. Platinum-DNA-binding levels of CS alone and in combinations with ART and OA.

Proteomics has analysed causes of drug resistance, in terms of the changes in protein expression, and has argued that ART and OA would be able to regulate the expression level of those proteins. Thus, proteins in the A2780 and A2780 ${ }^{\text {cisR }}$ cell lines were inspected by 2-D gel electrophoresis and mass spectrometry to examine their association with platinum drug resistance, wherein the protein expression levels in the A2780 ${ }^{\text {cisR }}$ cell line were compared to what was found in its counterpart cell line to determine the proteins that were differentially expressed. The objective of the proteomic study, 
besides the determination of new ovarian cancer biomarkers, was to evaluate the effect of: CS and ART (using 0/0 h), CS and OA (using 0/4 h), CS and ART (using 0/0 h), and CS and OA (using 0/0 h) on the expression of those dysregulated proteins (differently expressed proteins). Tables 7 and 8 show protein expression in: (1) untreated $\mathrm{A} 2780^{\mathrm{cisR}}$ as compared to the values found in the untreated A2780 cell line, and (2) treated A2780 ${ }^{\text {cisR }}$ cell line (with the chosen drug treatments, as mentioned above) as compared to the values that were detected in both untreated cell lines. In both situations, at the beginning, the A2780 cell line was used as a reference. Later, the A2780 cisR cell line was used as the reference. Proteins were considered to have undergone significant changes in expression if the fold factor was $\geq 2.0$. The proteins that were detected by MALDI TOF/TOF MS and were matched against the Mascot database (http://www.matrixscience.com) and the UniProtKB/Swiss-Prot database (http://www.uniprot.org/) [15], when A2780 and A2780 cisR cell lines alternatively were used as a reference, are illustrated in tables (Table S1 and Table 9. Accession number, protein ID, name and mass, MSMS, degree of coverage and score were obtained from APAF (http://www.proteome.org. $\mathrm{au} /$ ). Theoretical isoelectric point ( $\mathrm{pI}$ ), subcellular location, mass spectrum, and matched peptides were obtained from the Mascot database (http://www.matrixscience.com) and Swiss-Prot database (http://www.uniprot.org/) [15] through APAF (http://www.proteome.org.au/). In this study, 49 proteins out of 101 scored above 56, according to the Mascot parameter that protein scores above 56 are considered significant (see Mascot database (http://www.matrixscience.com), Swiss-Prot database (http://www.uniprot.org/) [15], and APAF (http://www.proteome.org.au/). Accordingly, those proteins were investigated for their involvement in the development of platinum resistance, besides evaluating the effect of the selected drug treatments on their expression. 
Table 7. List of protein expressions in A2780, compared to A2780 ${ }^{\text {cisR }}$ using A2780 as reference.

\begin{tabular}{|c|c|c|c|c|c|c|c|c|c|c|c|}
\hline Match ID & $\begin{array}{c}\text { Expression in } \\
\text { A2780 } \\
\text { cisk/A2780 }\end{array}$ & $\mathrm{CS}+\mathrm{ART}(4 / 0 \mathrm{~h})$ & $\mathrm{CS}+\mathrm{OA}(0 / 4 \mathrm{~h})$ & $\mathrm{CS}+\mathrm{ART}(0 / 0 \mathrm{~h})$ & $\mathrm{CS}+\mathrm{OA}(0 / 0 \mathrm{~h})$ & Match ID & $\begin{array}{c}\text { Expression in } \\
\text { A2780 } \\
\text { cisR/A2780 }\end{array}$ & $\mathrm{CS}+\mathrm{ART}(4 / 0 \mathrm{~h})$ & $\mathrm{CS}+\mathrm{OA}(0 / 4 \mathrm{~h})$ & CS + ART (0/0 h) & $\mathrm{CS}+\mathrm{OA}(0 / 0 \mathrm{~h}$ \\
\hline 1 & UR & & & PR & FUR & 48 & ND & & OR & & \\
\hline 3 & DR & PR & PR & PR & & 51 & DR & OR & PR & PR & PR \\
\hline 4 & DR & & & PR & PR & 52 & $\mathrm{ND}$ & $\mathrm{PR}$ & PR & OR & \\
\hline 5 & DR & PR & PR & PR & & 54 & DR & OR & OR & OR & OR \\
\hline 7 & DR & & & OR & & 55 & DR & & & PR & PR \\
\hline 8 & $\mathrm{ND}$ & PR & PR & OR & OR & 62 & DR & & & & \\
\hline 11 & ND & OR & & PR & & 63 & DR & & & PR & \\
\hline 12 & $\mathrm{ND}$ & $\mathrm{PR}$ & & $\mathrm{PR}$ & & 66 & $\mathrm{ND}$ & & & & \\
\hline 13 & DR & & PR & OR & OR & 68 & UR & & & & \\
\hline 14 & $\mathrm{NC}$ & & & OR & OR & 69 & DR & & & OR & OR \\
\hline 15 & UR & & & OR & OR & 70 & ND & & & OR & \\
\hline 16 & UR & PR & & PR & PR & 74 & ND & & OR & OR & \\
\hline 17 & ND & OR & PR & OR & OR & 76 & UR & & & & \\
\hline 19 & DR & OR & PR & OR & OR & 78 & ND & & & & \\
\hline 20 & ND & & & OR & OR & 82 & ND & & & & \\
\hline 21 & UR & & & & FUR & 85 & ND & & & & \\
\hline 25 & ND & & & OR & PR & 88 & ND & & & & \\
\hline 27 & ND & PR & OR & PR & & 89 & ND & & & FR & OR \\
\hline 29 & ND & OR & & & & 94 & ND & OR & OR & OR & OR \\
\hline 31 & ND & & PR & OR & & 95 & ND & OR & & & OR \\
\hline 32 & ND & & PR & OR & FR & 96 & ND & & & OR & OR \\
\hline 33 & ND & & PR & OR & $1 \pi$ & 97 & ND & OR & OR & הוב & \\
\hline 34 & ND & & OR & OR & & 98 & ND & & & & \\
\hline 35 & DR & & & PR & OR & 102 & ND & & & & \\
\hline 36 & UR & & OR & OR & PR & 103 & DR & & OR & & \\
\hline 39 & $\mathrm{ND}$ & & & & & 105 & ND & & & & \\
\hline 40 & DR & & & & & 106 & ND & & & OR & \\
\hline 42 & ND & & OR & OR & & 108 & ND & & & & \\
\hline 43 & ND & & & & & 111 & ND & & OR & & \\
\hline 44 & ND & & OR & & & 116 & UR & & $\mathrm{PR}$ & & PR \\
\hline 45 & DR & PR & FDR & FDR & FDR & 119 & ND & & & OR & \\
\hline 46 & DR & & & & & 120 & ND & & OR & & \\
\hline 47 & UR & OR & OR & OR & OR & 122 & ND & & & & \\
\hline
\end{tabular}

FR: fully restored (the expression level of the protein after treatment was the same as its expression level in the untreated A2780 cell line). OR: over restored (means the value of protein expression after treatment was \pm 0.05 , as compared to its level in the untreated A2780 cell line); FDR: further down-regulated (the combined treatment had a negative effect on protein expression where the expression decreased at least 0.05, below the expression level compared to its level in the untreated A2780 ${ }^{\text {cisR }}$ cell line); FUR: further up-regulated (the combined treatment has negatively affected the protein expression where the expression increased at least 0.05 , above the expression level compared to its level in the untreated A2780 PR: partially-restored; UP: up-regulated; DR: down-regulated; blank: spot was not detected after treatment with selected combination. 
Table 8. List of protein expressions in, A2780 cisR compared to A2780 using A2780 cisR as reference.

\begin{tabular}{|c|c|c|c|c|c|}
\hline Match ID & Expression in $\mathrm{A} 2780^{\text {cisR }} / \mathrm{A} 2780$ & CS + ART (4/0 h) & $\mathrm{CS}+\mathrm{OA}(0 / 4 \mathrm{~h})$ & CS + ART (0/0 h) & $\mathrm{CS}+\mathrm{OA}(0 / 0 \mathrm{~h})$ \\
\hline 8 & UR & & & & \\
\hline 9 & UR & OR & PR & PR & \\
\hline 11 & $\mathrm{DR}$ & OR & & OR & OR \\
\hline 12 & UR & & PR & OR & PR \\
\hline 13 & UR & PR & & OR & FR \\
\hline 16 & ND & & & & \\
\hline 18 & ND & OR & & PR & \\
\hline 19 & DR & & OR & OR & OR \\
\hline 22 & UR & PR & PR & PR & FUR \\
\hline 25 & UR & & & PR & \\
\hline 26 & UR & & FUR & & FUR \\
\hline 28 & DR & OR & & OR & \\
\hline 29 & ND & & & FUR & FUR \\
\hline 30 & UR & & OR & OR & PR \\
\hline 32 & UR & FUR & PR & FUR & FUR \\
\hline 41 & UR & & & PR & $\mathrm{PR}$ \\
\hline 44 & DR & & & PR & OR \\
\hline 46 & UR & & & PR & PR \\
\hline 47 & UR & & & OR & \\
\hline 50 & UR & & & & \\
\hline 56 & UR & & & & \\
\hline 57 & UR & & & & \\
\hline 58 & UR & & & PR & PR \\
\hline 59 & DR & & & & \\
\hline 61 & UR & & PR & & \\
\hline 62 & UR & & FUR & & \\
\hline 63 & UR & PR & PR & & \\
\hline 69 & DR & & & OR & \\
\hline
\end{tabular}

FR: fully restored (the expression level of the protein after treatment was the same as its expression level in the untreated A2780 cell line); OR: over restored (means the value of protein's expression after treatment is \pm 0.05 , as compared to its level in the untreated A2780 cell line); FDR: further down-regulated (the combined treatment had a negative effect on protein expression where the expression decreased at least 0.05 , below the expression level compared to its level in the untreated A $2780^{\text {cisR }}$ cell line): FUR: further up-regulated (the combined treatment has negatively affected the protein expression where the expression increased at least 0.05 , above the expression level compared to its level in the untreated A2780 $0^{\text {cisR }}$ cell line); blank: spot was not detected after treatment with selected combination; PR: partially-restored; UP: up-regulated; DR: down-regulated. 
Table 9. Characteristics of proteins that have undergone differential expressions in A2780 and A2780 $0^{\text {cisR }}$ cell lines following treatment with selected drug combinations using A2780 cisR cell line as reference.

\begin{tabular}{|c|c|c|c|c|c|}
\hline Mach ID & Protein ID & Full Name & Mascot Search Results & Location & References \\
\hline 8 & $\begin{array}{l}\text { ATP5H } \\
\text { O75947 }\end{array}$ & ATP synthase subunit $d$, mitochondrial & $\begin{array}{c}\text { Mass: } 18480 \\
\text { Mascot score: } 128 \\
\text { Coverage: } 57 \% \\
\text { pI: } 5.21 \\
\text { MS: } 11 \\
\text { MSMS: } 3\end{array}$ & Mitochondrion & $\begin{array}{c}{[15]} \\
\text { http://www.matrixscience.com }\end{array}$ \\
\hline 9 & $\begin{array}{c}\text { RAN } \\
\text { P62826 }\end{array}$ & GTP-binding nuclear protein Ran & $\begin{array}{c}\text { Mass: } 24408 \\
\text { Mascot score: } 132 \\
\text { Coverage: } 39 \% \\
\text { pI: } 7.01 \\
\text { MS: } 11 \\
\text { MSMS:1 }\end{array}$ & Nucleus & $\begin{array}{c}{[15]} \\
\text { http://www.matrixscience.com }\end{array}$ \\
\hline 12 & $\begin{array}{c}\text { PSA7 } \\
\text { O14818 }\end{array}$ & Proteasome subunit alpha type-7 & $\begin{array}{c}\text { Mass: } 27870 \\
\text { Mascot score: } 85 \\
\text { Coverage: } 39 \% \\
\text { pI: } 8.60 \\
\text { MS: } 10 \\
\text { MSMS: } 1\end{array}$ & Cytoplasm & $\begin{array}{c}{[15]} \\
\text { http://www.matrixscience.com }\end{array}$ \\
\hline 13 & $\begin{array}{c}\text { TPI } \\
\text { P60174 }\end{array}$ & Triosephosphate isomerase & $\begin{array}{c}\text { Mass: } 30772 \\
\text { Mascot score: } 340 \\
\text { Coverage: } 49 \% \\
\text { pI: } 5.65 \\
\text { MS: } 20 \\
\text { MSMS:3 }\end{array}$ & & $\begin{array}{c}{[15]} \\
\text { http://www.matrixscience.com }\end{array}$ \\
\hline 16 & $\begin{array}{l}\text { VDAC1 } \\
\text { P21796 }\end{array}$ & $\begin{array}{l}\text { Voltage-dependent anion-selective } \\
\text { channel protein } 1\end{array}$ & $\begin{array}{c}\text { Mass: } 30754 \\
\text { Mascot score: } 368 \\
\text { Coverage: } 51 \% \\
\text { pI: } 8.62 \\
\text { MS: } 12 \\
\text { MSMS: } 3\end{array}$ & $\begin{array}{l}\text { Mitochondrion outer } \\
\text { membrane }\end{array}$ & $\begin{array}{c}{[15]} \\
\text { http://www.matrixscience.com }\end{array}$ \\
\hline
\end{tabular}


Table 9. Cont

\begin{tabular}{|c|c|c|c|c|c|}
\hline Mach ID & Protein ID & Full Name & Mascot Search Results & Location & References \\
\hline 18 & $\begin{array}{c}\text { hnRNPA2/B1 } \\
\text { P22626 }\end{array}$ & $\begin{array}{l}\text { Heterogeneous nuclear } \\
\text { ribonucleoproteins A2/B1 }\end{array}$ & $\begin{array}{c}\text { Mass: } 37407 \\
\text { Mascot score: } 258 \\
\text { Coverage: } 48 \% \\
\text { pI: } 8.97 \\
\text { MS: } 21 \\
\text { MSMS: } 6\end{array}$ & Nucleus, nucleoplasm & $\begin{array}{c}{[15]} \\
\text { http://www.matrixscience.com }\end{array}$ \\
\hline 22 & $\begin{array}{l}\text { PGK1 } \\
\text { P00558 }\end{array}$ & Phosphoglycerate kinase 1 & $\begin{array}{c}\text { Mass: } 44586 \\
\text { Mascot score: } 145 \\
\text { Coverage: } 48 \% \\
\text { pI: } 8.30 \\
\text { MS: } 22 \\
\text { MSMS: } 1\end{array}$ & Cytoplasm & $\begin{array}{c}{[15]} \\
\text { http://www.matrixscience.com }\end{array}$ \\
\hline 25 & $\begin{array}{c}\text { GOT1 } \\
\text { P17174 }\end{array}$ & Glutamate oxaloacetate transaminase 1 & $\begin{array}{c}\text { Mass: } 46219 \\
\text { Mascot score: } 331 \\
\text { Coverage: } 66 \% \\
\text { pI: } 6.52 \\
\text { MS: } 27 \\
\text { MSMS: } 6\end{array}$ & Cytoplasm & $\begin{array}{c}{[15]} \\
\text { http://www.matrixscience.com }\end{array}$ \\
\hline 30 & $\begin{array}{l}\text { EF1A1 } \\
\text { P68104 }\end{array}$ & Elongation factor 1-alpha 1 & $\begin{array}{c}\text { Mass: } 50109 \\
\text { Mascot score: } 135 \\
\text { Coverage: } 25 \% \\
\text { PI: } 9.10 \\
\text { MS: } 13 \\
\text { MSMS: } 2\end{array}$ & Cytoplasm & $\begin{array}{c}{[15]} \\
\text { http://www.matrixscience.com }\end{array}$ \\
\hline 32 & $\begin{array}{l}\text { ACTG } \\
\text { P63261 }\end{array}$ & Actin, cytoplasmic 2 & $\begin{array}{c}\text { Mass: } 41766 \\
\text { Mascot score: } 598 \\
\text { Coverage: } 55 \% \\
\text { pI: } 5.31 \\
\text { MS: } 26 \\
\text { MSMS:5 }\end{array}$ & Cytoplasm, cytoskeleton & $\begin{array}{c}{[15]} \\
\text { http://www.matrixscience.com }\end{array}$ \\
\hline 41 & $\begin{array}{l}\text { KPYM } \\
\text { P14618 }\end{array}$ & Pyruvate kinase PKM & $\begin{array}{c}\text { Mass: } 57900 \\
\text { Mascot score: } 188 \\
\text { Coverage: } 33 \% \\
\text { pI: } 7.96 \\
\text { MS: } 23 \\
\text { MSMS: } 3\end{array}$ & Cytoplasm. & $\begin{array}{c}{[15]} \\
\text { http://www.matrixscience.com }\end{array}$ \\
\hline
\end{tabular}


Table 9. Cont.

\begin{tabular}{|c|c|c|c|c|c|}
\hline Mach ID & Protein ID & Full Name & Mascot Search Results & Location & References \\
\hline 44 & $\begin{array}{l}\text { P4HB } \\
\text { P07237 }\end{array}$ & Prolyl 4-hydroxylase subunit beta & $\begin{array}{c}\text { Mass: } 57081 \\
\text { Mascot score: } 433 \\
\text { Coverage: } 50 \% \\
\text { PI: } 4.76 \\
\text { MS: } 29 \\
\text { MSMS: } 6\end{array}$ & $\begin{array}{l}\text { Endoplasmic reticulum } \\
\text { lumen }\end{array}$ & $\begin{array}{c}{[15]} \\
\text { http://www.matrixscience.com }\end{array}$ \\
\hline 57 & $\begin{array}{l}\text { APG2 } \\
\text { P34932 }\end{array}$ & Shock 70-related protein APG-2 & $\begin{array}{c}\text { Mass: } 94271 \\
\text { Mascot score: } 125 \\
\text { Coverage: } 25 \% \\
\text { pI: } 5.11 \\
\text { MS: } 22 \\
\text { MSMS:3 }\end{array}$ & Cytoplasm (Probable) & $\begin{array}{c}{[15]} \\
\text { http://www.matrixscience.com }\end{array}$ \\
\hline 58 & $\begin{array}{l}\text { VINC } \\
\text { P18206 }\end{array}$ & Vinculin & $\begin{array}{c}\text { Mass: } 123722 \\
\text { Mascot score: } 226 \\
\text { Coverage: } 34 \% \\
\text { pI: } 5.50 \\
\text { MS: } 40 \\
\text { MSMS:4 }\end{array}$ & Cytoplasm, cytoskeleton & $\begin{array}{c}{[15]} \\
\text { http://www.matrixscience.com }\end{array}$ \\
\hline 63 & $\begin{array}{c}\text { EF2 } \\
\text { P13639 }\end{array}$ & Elongation factor 2 & $\begin{array}{c}\text { Mass: } 95277 \\
\text { Mascot score: } 425 \\
\text { Coverage: } 27 \% \\
\text { pI: } 6.41 \\
\text { MS: } 39 \\
\text { MSMS:7 }\end{array}$ & Cytoplasm & $\begin{array}{c}{[15]} \\
\text { http://www.matrixscience.com }\end{array}$ \\
\hline 69 & $\begin{array}{l}\text { CLIC1 } \\
\text { O00299 }\end{array}$ & Chloride intracellular channel protein 1 & $\begin{array}{c}\text { Mass: } 26906 \\
\text { Mascot score: } 158 \\
\text { Coverage: } 47 \% \\
\text { pI: } 5.09 \\
\text { MS: } 11 \\
\text { MSMS: } 3\end{array}$ & Nucleus & $\begin{array}{c}{[15]} \\
\text { http://www.matrixscience.com }\end{array}$ \\
\hline
\end{tabular}




\section{Discussion}

\subsection{Cytotoxicity of Single Drug}

The results show that OA showed greater activity against A2780 cisR and A2780 ZD0473R cell lines than against parent A2780 cell line, ART showed greater sensitivity towards A2780 and A2780 cisR than A2780 ZD0473R cells while CS showed lower activities towards A2780 cisR and A2780ZD0473R cell lines than the parent cell line. It has been reported that most of the natural products can modify several factors involved in the oncogenic transcription such as; Nrf-2, Hh /GLI, STAT3, FoxM1, PPAR y, Wnt/ $\beta$-catenin, HGFR, HIF1 $\alpha$, AP-1 and NF- $\mathrm{B}$ [16]. In contrast, aberrant expression of STAT3, HIF1 $\alpha$, NF- $\mathrm{B}, \mathrm{AP}-1$ and FoxM1 are often observed in different types of cancers [16]. That OA was found to be more active against A2780 ${ }^{\text {cisR }}$ and A2780 $\mathrm{ZD0473R}$ cell lines may be attributed to its apoptotic effect, including the enhancement of p38 MAPK, ASK1 and ROS, and its inhibition effect of signalling pathways such as; S6K, PI3K, mTOR, Akt and NF-kB [10]. These functions make the OA more active towards platinum resistant cells.

\subsection{Combination Indices}

The results show that the synergistic (Figures 2 and 3 and Tables 2-4) effect from the combinations of CS with OA and ART were dependent on the dose and the sequence of administration in the three cell lines. The synergism from combination of OA and ART with CS, however, is not surprising given the fact that OA and ART are known as apoptotic inducers (through increasing Bax, decreasing Bcl-2, and up-regulating of caspases), as well as they exhibit tumour inhibition effect (through the down-regulation of NF-кB and other signalling pathways) and anti-angiogenic effect (through the decreasing of VEGF) [10,17]. Hence, growth inhibition resulting from combination of OA and ART with CS may be attributed to the down regulation of Bcl-2 and NF- $\mathrm{BB}$ pathways. Additionally, synergistic outcomes can be ascribed to the effect of ART on cell-cycle that involves suppression of CDK4 and CDK2 expressions [13] as well as inhibition of cyclin A, cyclin E, cyclin D3, cyclin D1, CDK6, E2F1, and JAB1 transcriptions with enhancement of IFIT3, p21, and p27 [17]. Furthermore, it is likely that the significant increase in growth inhibition may be partly attributed to OA's anticancer effect through the regulation of various signalling cascades, including the inhibition of S6K, PI3K, mTOR, Akt, and NF- $\mathrm{B}$ signalling pathways [10]. The reason why $0 / 0 \mathrm{~h}$ sequence of administration of CS in combinations with ART and OA have generally produced the most synergistic outcomes, may be attributed to the time-dependent nature of the actions of ART and OA. In addition, Ziberna et al. reported that, in different multi-drug resistant cancer cell lines, OA exerts its apoptotic effect via the enhancement of p38 MAPK, ASK1, and ROS pathways in time- and concentration-dependent fashion [10]. Similar to our results, enhanced growth inhibition in HCC was observed from co-administration of OA and sorafenib (chemotherapeutic drug) [10]. It is possible that presence of ART or OA might influence platinum influx and efflux, apoptosis induction, Pt-DNA adducts tolerance, and DNA repair. In support of the idea, it may be noted that Ziberna et al. suggested that intracellular concentration levels of chemotherapeutic drugs were enhanced because of OA's ability to inhibit the efflux transporters [10]. The combination of OA with 5-fluorouracil also produced synergistic effect and induced apoptosis in pancreatic cancer. Thus, it was suggested that the combining of OA with other chemotherapeutic drugs would produce synergistic anticancer effect [10]. A previous study, using ICP-MS has found differential cellular uptakes in the cisplatin-sensitive ovarian carcinoma A2780 and cisplatin-resistant ovarian carcinoma A2780 cisR, where the Pt levels in the resistant cell line were found to be significantly lower [18], suggesting, that resistance could be partially attributed to a decrease in the intracellular drug concentration [18]. Another study using ICP-MS to measure platinum levels has also shown that that A2780 cells accumulate more than twofold of platinum than wild-type p53 A2780/CP70 (cisplatin-resistant) cells [19]. Moreover, measuring platinum at the level of a single cell using Single Cell ICP-MS method in ovarian cancer cell lines A2780 and A2780/CP70 shows that the cisplatin uptake is lower in the cisplatin resistant A2780/CP70 cell line [20]. 


\subsection{Cellular Accumulation of Platinum}

The results showed that $\mathrm{Pt}$ accumulations (Table 5 and Figure 2) from combination of CS with the chosen drugs were always greater than that from CS alone, irrespective of nature of the combined drug action. For example, CS in combination with ART and OA using $0 / 0 \mathrm{~h}$ have produced greater $\mathrm{Pt}$ accumulations than those from the other sequences in the A2780 cell line. The Pt level from synergistic combination of CS with ART using 0/0 $\mathrm{h}$ was 2.9 times higher than the levels from the treatment with $(4 / 0 \mathrm{~h})$ combination of the compounds in the same cell line. Additionally, Pt level from the synergistic combination of CS and ART using 0/4 h, in A2780 cells, was about four times greater from the synergistic $4 / 0 \mathrm{~h}$ combination in the same cell line. Moreover, platinum level resulting from the synergistic $0 / 0 \mathrm{~h}$ combination of CS with ART showed three times higher value than that from $0 / 4 \mathrm{~h}$ combination in A2780 cisR cells and 8.5 times higher than that from CS alone. Furthermore, in A2780 cisR cells, Pt level resulted from the synergistic $4 / 0 \mathrm{~h}$ combination of CS and ART was nearly two times greater than that from synergistic $0 / 4 \mathrm{~h}$ combination and 4.5 times greater than that from CS alone. Together, these findings provide further support for the hypothesis that the ART growth inhibition action is a sequence and cell type dependent. The results are in agreement with the findings of Gong et al., wherein they reported that ART action was a cell type dependent [13]. On the other hand, synergistic combination of CS with OA using 0/0 h combination in A2780 cells, has increased Pt level to around 15 times greater than that from CS alone, 8.2 and 10 times greater than that from the synergistic sequences of $0 / 4 \mathrm{~h}$ and $4 / 0 \mathrm{~h}$, respectively. Furthermore, it was found that in the A2780 cisR cell line, Pt level from synergistic combination of CS with OA using $0 / 0 \mathrm{~h}$ sequence was nearly two times greater than that from treatment with $0 / 4 \mathrm{~h}$ combination and 3.3 times greater than that from CS alone. Moreover, treatment with synergistic combination 4/0 h, CS accumulation was 1.3 times greater than that resulted from $0 / 0 \mathrm{~h}$ combination and four times greater than that from CS alone. It appears that intracellular accumulation of CS in the presence of OA is also sequence-dependent. Thus, the observed increase in CS accumulation could be attributed to either the ability of OA to increase the influx of CS or to decrease CS efflux or both. The findings are supported by those of Ziberna et al., wherein they reported that intracellular concentration levels of chemotherapeutic drugs were enhanced because of OA's ability to inhibit the efflux transporters [10]. The inconsistency may be due to the fact that actions of OA are time- and concentration-dependent [10].

\subsection{Platinum-DNA Binding Level}

Generally, platinum-DNA levels were greater in the A2780 cisR cells than in A278 cells. A possible explanation is that the presence of ART and OA might have modulated some of the platinum resistance mechanisms, such as decreases in platinum-DNA adducts formation [21], increased platinum detoxification, and increased DNA repair [22]. Another possible explanation is that the compounds led to an increase in the platinum uptake so that more platinum was available to bind DNA. Additionally, the compounds could have prevented efflux of the platinum so that the platinum had more chance to cause DNA damages before being deactivated. A combination of CS with ART and OA increased Pt-DNA binding levels, which are consistent with the observed increase in Pt accumulation resulting from the combination of CS with the phytochemicals. Overall, the results presented in (Table 6) showed that with the combinations of CS with ART and OA in the A2780 cell line, platinum-DNA binding levels were not always higher than those of CS alone. For example, in A2780 cell line, platinum-DNA binding levels from synergistic combination of CS with OA using $0 / 4 \mathrm{~h}$ sequence and synergistic combination of CS with ART using 4/0 h sequence were significantly lower than that from CS alone. These results have highlighted the complexity of the situation due to involvement of multiple pathways associated with apoptosis and drug resistance, including the interaction between ART and OA with CS. It can thus be suggested that the variations in the overall outcomes could be attributed to: (1) the dual behaviour of most of the phytochemicals as antioxidant agent (protective effect) at low concentrations and as a pro-oxidant (apoptotic) enhancement at high concentrations; (2) concentration and time dependent effect of the phytochemicals; (3) growth inhibitory effect of platinum drugs as stated previously not 
being merely dependent on abilities to bind to DNA (although it is an essential step, but not sufficient for the apoptosis induction); (4) ROS formed by platinum drugs, for example cisplatin, is dependent on its concentration and the duration of exposure [18]; thereby, enhancing apoptosis induction [21]. For instance, in this study $24 \mathrm{~h}$ incubation period was used as against $72 \mathrm{~h}$ for studies on cytotoxicity that may contribute to the overall outcomes. Finally, it has been reported that platinum resistance might have resulted from enhanced tolerance [23], reduction in the adducts formation [18], and enhanced DNA damage repair [24].

\subsection{In Proteomics Study Involving 2-D Gel Electrophoresis}

A total of 133 spots were identified, out of which 101 proteins were significantly altered in expression. Among them, 54 spots were successfully identified by MS. In some cases, mass spectral analysis showed that the same protein was named for more than one spot such as spots 16, 18, and 76 were assigned to hnRNPA2/B1, spots 17 and 31 were assigned to ENOA, spots 52 and 63 were assigned to EF2, and spots 36 and 96 were assigned to VIME. Assignment of different spots to the same protein that exists in multiple isoforms with different $p I s$, might be attributed to the post-translational modifications, which was suggested to occur in 2-D gel electrophoresis-based proteomics studies [24,25], thus, reducing the total to (49) proteins. Based on the protein functions, proteins differentially expressed in the $\mathrm{A} 2780^{\mathrm{cisR}}$ cell line were divided into nine major groups as discussed in the next section, using A2780 and A2780 $0^{\text {cisR }}$ cell lines alternatively as a reference, and are illustrated in Tables 10 and 11.

Table 10. Functional classification of the proteins that are differentially expressed in the A2780 cisR cell line compared to the A2780 cell line due to treatment using the parent cell line A2780 as reference.

\begin{tabular}{|c|c|c|}
\hline Match ID & $\mathrm{A} 2780^{\mathrm{cisR}} / \mathrm{A} 2780$ & Protein ID \\
\hline \multicolumn{3}{|c|}{ Stress and Chaperones } \\
\hline 3 & DR & CYPA \\
\hline 32 & ND & ТСРВ \\
\hline 35 & DR & ERp57 \\
\hline 39 & ND & ТСРН \\
\hline 45 & DR & HSP7C \\
\hline 46 & DR & mortalin \\
\hline 47 & UP & BIP \\
\hline 51 & DR & HSP90B \\
\hline 54 & DR & GRP94 \\
\hline 88 & ND & Hop \\
\hline 105 & ND & TCPA \\
\hline \multicolumn{3}{|c|}{ Metabolism and Biosynthetic Processes } \\
\hline 11 & ND & PGAM1 \\
\hline $17 / 31$ & ND & ENOA \\
\hline 19 & DR & LDHB \\
\hline 33 & ND & SERA \\
\hline 55 & DR & IMMT \\
\hline 63 & DR & NM23 \\
\hline 97 & ND & ATPA \\
\hline 95 & ND & PSAT \\
\hline \multicolumn{3}{|c|}{ Cytoskeletal Proteins } \\
\hline 5 & DR & P18 \\
\hline $36 / 96$ & UR & VIME \\
\hline 94 & ND & GBLP \\
\hline 108 & ND & $\mathrm{CAH} 2$ \\
\hline \multicolumn{3}{|c|}{ Initiation and Elongation } \\
\hline 25 & ND & EFTU \\
\hline 4 & DR & EIF5A1 \\
\hline 27 & ND & EF1G \\
\hline 52 & ND & EF2 \\
\hline
\end{tabular}


Table 10. Cont.

\begin{tabular}{|c|c|c|}
\hline Match ID & $\mathrm{A} 2780^{\mathrm{cisR}} / \mathrm{A} 2780$ & Protein ID \\
\hline \multicolumn{3}{|c|}{ mRNA Processing Proteins } \\
\hline 15 & UR & hnRNPA1 \\
\hline $16 / 76$ & UR & hnRNP A2/B1 \\
\hline \multicolumn{3}{|c|}{ Detoxification and Drug Resistance } \\
\hline 8 & ND & PRDX1 \\
\hline 66 & ND & PRDX6 \\
\hline \multicolumn{3}{|c|}{ Cell Cycle Regulation and Cell Proliferation } \\
\hline 7 & DR & Op18 \\
\hline 89 & ND & MCM7 \\
\hline \multicolumn{3}{|c|}{ Signal Transduction and Cell Cycle } \\
\hline 13 & DR & $1433 Z$ \\
\hline \multicolumn{3}{|c|}{ Protein Synthesis and Degradation } \\
\hline 69 & DR & PSA3 \\
\hline
\end{tabular}

DR: Down-regulated; UR: Up-regulated; ND: Not-detected.

Table 11. Functional classification of the proteins that are differentially expressed in the A2780 ${ }^{\text {cisR }}$ cell line compared to the A2780 cell line due to treatment using the A2780 ${ }^{\text {cisR }}$ cell line as reference.

\begin{tabular}{|c|c|c|}
\hline Match ID & $\mathrm{A} 2780^{\mathrm{cisR}} / \mathrm{A} 2780$ & Protein ID \\
\hline \multicolumn{3}{|c|}{ Stress and Chaperones } \\
\hline 44 & DR & $\mathrm{P} 4 \mathrm{HB}$ \\
\hline 57 & UR & APG2 \\
\hline \multicolumn{3}{|c|}{ Metabolism and Biosynthetic Processes } \\
\hline 13 & UR & TPI \\
\hline 8 & UR & АТР5H \\
\hline 25 & UR & GOT1 \\
\hline 16 & UR & VDAC1 \\
\hline 41 & UR & KPYM \\
\hline \multicolumn{3}{|c|}{ Cytoskeletal Proteins } \\
\hline 32 & UR & ACTG \\
\hline 58 & UR & VINC \\
\hline \multicolumn{3}{|c|}{ Initiation and Elongation } \\
\hline 30 & UR & EF1A1 \\
\hline 63 & UR & EF2 \\
\hline \multicolumn{3}{|c|}{ mRNA Processing Proteins } \\
\hline 18 & ND & hnRNP A2/B1 \\
\hline \multicolumn{3}{|c|}{ Detoxification and Drug Resistance } \\
\hline 22 & UR & PGK1 \\
\hline \multicolumn{3}{|c|}{ Cell Cycle Regulation and Cell Proliferation } \\
\hline 69 & $\mathrm{DR}$ & CLIC1 \\
\hline \multicolumn{3}{|c|}{ Signal Transduction and Cell Cycle } \\
\hline 9 & UR & RAN \\
\hline \multicolumn{3}{|c|}{ Protein Synthesis and Degradation } \\
\hline 12 & UR & PSA7 \\
\hline
\end{tabular}

DR: Down-regulated; UR: Up-regulated; ND: Not-detected. 
Mortalin, also known as GRP75 [15], a member of chaperones and stress related proteins, which plays essential function in mitochondrial proteins folding [26], cancer cell proliferation, and enhancement of angiogenesis [27]. In this study, mortalin was found to be down-regulated in the cisplatin-resistant $\mathrm{A} 2780^{\text {cisR }}$ cell line as compared to the sensitive A2780 cell line, consistent with the earlier studies [28-30]. The findings indicate that mortalin may play a role drug resistance, representing mortalin as potential diagnostic and therapeutic targets. Treatments with the synergistic combinations of (CS and OA using $0 / 0 \mathrm{~h}$ ) and (CS and ART using $0 / 0 \mathrm{~h}$ ), partially restored mortalin expression in $\mathrm{A} 2780^{\mathrm{cis} R}$ cell line, suggesting that the applied treatments have improved chaperone action towards greater cell kill.

APG2 is another molecular chaperone and stress related protein, also known as HSP74 [15], is ubiquitously expressed in different organs [31]. In this study APG2 was over-expressed in the cisplatin-resistant $\mathrm{A} 2780^{\mathrm{cisR}}$ cell line as compared to the sensitive A2780 cell line. Up-regulation of APG2 was previously reported in hepatocellular carcinomas [31]. The elevated expression was related to drug resistance, poor prognosis or advanced stages in different type of cancers [31]. The findings indicate that APG2 plays a role in the development of drug resistance, suggesting that APG2 can be a potential prognostic and therapeutic target. Expression of APG2 was lowered below threshold of detection after treatment with synergistic combinations of (CS and ART using 4/0 h), (CS and OA using 0/4), (CS and ART using 0/0 h) and (CS and OA using 0/0), that might have inhibited its behaviour as heat shock protein exposing cells to the toxic effect of CS, thereby increased cell apoptosis, indicating a causal relationship between APG2 expression and platinum resistance in ovarian cancer.

BIP, also known as GRP78 [15], was over-expressed in a large number of cancers, including malignant gliomas, lung cancer, and breast cancer [32]. It enhances tumour metastasis, survival, proliferation, and resistance to a wide range of therapies [33], including cisplatin [34]. In line with reported findings, in the present study, BIP was up-regulated in the A2780 ${ }^{\text {cisR }}$ cell line as compared to A2780 cell line. Treatment with selected combinations, over-restored BIP expression, indicating that the treatments have prevented BIP's roles in cell protection and the tumorigenicity of cancer cells, and thereby increasing the death of cells exposed to CS, suggesting that the selected combinations can serve as alternative therapeutic methods for the resistance in ovarian cancer associated with abnormal BIP expression. Thus, it seems that BIP may possibly be playing a major role in these synergistic outcomes.

HSP90B, also known as HS90B [15], is one of the HSP90 isoforms found in mammalian cells [35,36]. HSP90 is involved in the differentiation and cell proliferation processes [37]. It exhibits an anti-apoptotic effect through modulation of NF- $\mathrm{KB}, \mathrm{TNF}$, and AKT pathways and enhances tumour growth and angiogenesis through the VEGF pathway [38]. In the present study, HSP90B was down-regulated in the cis-resistant cell line as compared to A2780 cell line, consistent with the findings of earlier studies $[21,26,27]$. The findings indicate that HSP90B plays an important role in apoptosis pathway and in the development of drug resistance. HSP90B expression was partially/over-restored after the treatment with the selected combinations, possibly be due to the effect of the treatments on HSP90B capability to interact with survival signal, including NF- $\mathrm{KB}$ and AKT, leading to their inactivation thereby sensitizing cells to apoptosis mediated by the stresses produced by CS. Hence restoration of HSP90B can be a contributing factor responsible for apoptosis enhancement so that the level of its expression can be a means for drug resistance in ovarian cancer.

GRP94 also known as ENPL [15], is a member of hsp90 family. The high level of GRP94 was found in many cancers such as breast, gastric, oesophageal, colon, lung, and breast cancer [39]. However, in the present study, GRP94 was down-regulated in the cisplatin-resistant A2780 cisR cell line as compared to A2780 cell line. The result is consistent with the findings of earlier studies $[24,28,30]$. Collectively, the findings suggest that GRP94 expression is cell and cancer dependent and suggest GRP94 as being a potential diagnostic and therapeutic target. Treatment with selected combinations over-restored GRP94 expression. Together with the fact that the GRP94, as one member of HSPs family, protects cells from stressful stimuli, suggests that this protein could play a role in tumorigenicity and 
drug resistance in ovarian. Thus, the result supports the possibility of a causal relationship between GRP94 expression and the resistance caused by CS.

CYPA is one of CyPs isoforms (also known as PPIA) [15]. CYPA catalyses cis-trans isomerization of the peptide bonds $[15,40]$. CYPA is up-regulated in glioblastoma multiforme, melanoma, colorectal, breast and pancreatic cancer [41]. In contrast in the present study, CYPA was down-regulated in the cis-resistant cell line as compared to the sensitive A2780 cell line, consistent with the findings of the earlier studies $[29,30]$. The results suggest that CYPA is involved in drug resistance in ovarian cancer, Treatment with synergistic combinations of (CS and ART using 4/0 h), (CS and OA using 0/4 h) (CS and ART using 0/0 h) partially restored CYPA expression. While after treatment with (CS and OA using 0/0 h) CYPA was not detectable, suggesting that its expression is very sensitive to the treatment. Where the enhanced apoptosis be brought about may be the result of OA's signalling inhibitory mechanism and its ROS production that have modulated CYPA activities of antioxidant stabilization, transcriptional control, trafficking, cell cycle regulation and signal transduction [42]. Thus, the results suggest that there is a strong correlation between CYPA expression and apoptosis; thus the chosen treatments can serve as potential approaches to overcome drug resistance associated with atypical CYPA expression.

P4HB is one member of the PDI family, and is also known as PDIA1 [15]. It has multifunctional activities besides its involvement in the disulphides breakage, formation, and rearrangement at different cellular locations [43]. P4HB is up-regulated in glioblastoma cancer [44]. Silencing of P4HB inhibits tumour survival of MCF-7 cells; however, it did not show a significant inhibitory effect on HeLa cells [44]. Thus, it has been suggested that $\mathrm{P} 4 \mathrm{HB}$ expression is a cell-type dependent [44]. In the present study, $\mathrm{P} 4 \mathrm{HB}$ was down-regulated in A2780 $0^{\text {cisR }}$ cell line as compared to sensitive A2780 cell line. The result is in accordance with the previous findings of the earlier studies $[24,28,30]$. The data clearly points to roles of $\mathrm{P} 4 \mathrm{HB}$ in cancer progression and resistance, while its expression is cell and cancer-dependent. Treatment with synergistic combinations of (CS and OA using 0/0 h) over-restored P4HB expression. Whereas, treatment with synergistic combinations of (CS and ART using $0 / 0 \mathrm{~h}$ ) partially restored P4HB expression, suggesting the involvement of $\mathrm{P} 4 \mathrm{HB}$ in apoptotic pathway and indicating that the rise in growth inhibition was caused by the increased P4HB expression. Therefore, the selected combinations are effective in overcoming drug resistance in ovarian cancer model.

ERp57 is another member of the PDI family, also known as Erp60, PDIA3, and GRP58 [15], is a chaperone, oxidoreductase and disulphide isomerase protein [45]. ERp57 plays a crucial role along with CRT and CNX chaperones in folding process of disulphide bond-containing proteins and highly glycosylated [46]. It reacts with Ref-1 and STAT3, and involved in the formation of STAT3-DNA complexes [47]. Although, ERp57 was reported to be up-regulated in cervical [47], liver, breast,rectal, thyroid and gastric cancer [48]. It was significantly down-regulated in the most of metastases and primary gastric cancers [49]. Similarly, in this study, ERp57 was down-regulated in cis-resistant cell line as compared to the sensitive counterpart cell line. Thus, the result together with literature data, indicate that dysregulation of the ERp57 expression enhances drug resistance and cancer progression while its level of expression is highly dependent on cell and cancer type. Hence, ERp57 may serve as a beneficial diagnostic marker and therapeutic target. Treatment of A2780 cisR cell line with synergistic combination of (CS and OA using 0/0 h) over-restored ERp57 expression while (CS and ART using 0/0 h) partially restored its expression, indicating a causal relationship between ERp57 expression and platinum resistance in ovarian cancer.

PGAM1, also known as PGAMA [15], is a glycolytic enzyme that converts 3-PG to 2-PG [47]. PGAM1 was over-expressed in different types of cancer such as hepatocellular carcinoma, breast carcinoma and colorectal cancer [50]. In the present study, PGAM1was not detected in A2780 $0^{\text {cisR }}$ cells, possibly due to very low concentration. Given the important role of PGAM1 in the energy production associated with cell growth and cell proliferations, suggesting that PGAM1 may possibly be serving as a potential biomarker and therapeutic means towards Pt-resistance in ovarian cancer. Treatment with synergistic combination of (CS and ART using 4/0 h) over-restored PGAM1 expression, while treatment 
with synergistic combinations of (CS and ART using 0/0 h) partially restored PGAM1 expression. Whereas, after treatment with synergistic combinations of (CS and OA using $0 / 0 \mathrm{~h}$ ) and (CS and OA using $0 / 4 \mathrm{~h}$ ) PGAM1 expression was below threshold of detection. The results imply that level of PGAM1 expression was extremely sensitive towards the treatments that inhibited its ability to produce energy to nourish cancer cells thereby increased their vulnerability to the platinum drug. Hence, restoration of PGAM1 can be a contributing factor responsible for apoptosis enhancement so that the level of its expression can be a means for drug resistance in ovarian cancer. Therefore, chosen combinations can be helpful in sensitizing resistant cells towards platinum drugs and decreasing their side effects.

$L D H B$, also known as LDH-H [15], is involved in conversion of lactate to pyruvate [51]. LDHB was over-expressed in archival metastatic melanoma [52] and nasopharyngeal carcinoma [53]. However, it was found to be down-regulated in the MHCC97-H hepatocellular carcinoma cell strain against less metastatic MHCC97-L cell strain [54], and in the highly metastatic gallbladder carcinoma (GBC-SD18H) versus (GBC-SD18L) less potential metastasis cell line [55]. Similarly, in this study LDHB was down-regulated in the $\mathrm{A} 2780^{\text {cisR }}$ cell line as compared to sensitive counterpart cell line. The findings indicate that aberrant LDHB expression is cell, stage and cancer type dependent, hence, targeting LHDB expression level would be beneficial diagnostic and therapeutic strategies. LDHB expression was partially/over-restored after treatment with the chosen combinations, supporting the idea that synergistic outcomes, besides other reasons are associated with enhancement of CS cytotoxic effects by ART and OA through LHDB restoration which have modulated its role in energy metabolism, suggesting a strong correlation between LDHB expression and apoptosis improvement.

ATPA, also known as ATP5A1, is a mitochondrial enzyme involved in the synthesis of ATP from ADP [15]. Over-expression of ATPA was observed in breast cancer cell (MCF7) [56], anaplastic thyroid cancer [57], acute lymphoblastic leukaemia [58], multidrug resistant cervical carcinoma (MDR) KB-v1 cells [59], and resistant leukaemia cells [60]. However, ATPA was down regulated in clear cell renal cell carcinoma [61], and chromophobe renal cell carcinoma [62]. In this study, ATPA was not detectable in A2780 $0^{\text {cisR }}$ cell line as compared to its sensitive counterpart, possibly due to low concentration. The findings suggest that the dysregulation of ATPA level contributes to carcinogenesis event and targeting this protein might be of therapeutic importance. Treatment with synergistic combinations of (CS and OA using $0 / 4 \mathrm{~h}$ ) and (CS and ART using $4 / 0 \mathrm{~h}$ ) over restored its expression. ATPA expression after treatment with synergistic combinations of (CS and ART using 0/0 h) and (CS and OA using 0/0 h) was not detectable, suggesting that the nominated combinations are extremely effective in overcoming drug resistance in ovarian cancer model.

ATP5H "generates ATP from ADP in the existence of a proton gradient throughout the membrane." [15]. ATP5H is overexpressed in lung adenocarcinomas [63] and MCF7 cell line [56]. Consistent with the reported findings, in the current study, ATP5H expression was up-regulated in $\mathrm{A} 2780^{\mathrm{cisR}}$ cell line as compared to the level found in sensitive A2780 cell line. The data point to the contribution of ATP5H in cancer formation and suggest that ATP5H may serve as a possible diagnostic marker and molecular target. ATP5H expression after the treatment with synergistic combinations of (CS and OA using 0/4 h), (CS and ART using 4/0 h), (CS and OA using 0/0 h), and (CS and ART using $0 / 0 \mathrm{~h}$ ) was not detectable, suggesting that ATP5H expression is very sensitive to the combinations. Hence, these combinations would in helpful in opposing resistance in ovarian cancer.

TPI also known as TIM [15], is involved in the pathway of energy metabolism through catalysing the interconversion of DHAP to GAP [64]. TPI expression level was over-expressed in bladder squamous cell [61], prostate, lymph node, kidney, skin, testis, stomach, brain [65], epithelial ovarian cancer paclitaxel resistant A2780TC1 cells versus its sensitive cell line [66], and hepatocellular carcinoma versus normal tissues [50]. This is consistent with the current study wherein TPI was up-regulated in ovarian cancer cis-resistant versus its sensitive cell line. The findings suggest that dysregulation of TPI expression is playing a role in cancer promotion and drug resistance. Thus, it can be said that TPI can serve as potential biomarker and therapeutic targets. Treatment of A2780 cell line with synergistic combination of (CS and ART using 0/0 h) over-restored TPI expression. While treatment 
of A2780 cisR cell line with synergistic combination of (CS and ART using 4/0 h) partially restored its expression. Whereas, treatment with synergistic combination of (CS and OA using $0 / 0 \mathrm{~h}$ ) fully-restored its expression, suggesting a strong correlation between TPI expression and improved cell kill.

GOT1, alternatively named as AATC [15], catalyses the interconversion of $\alpha$-ketoglutarate and aspartate to glutamate and oxaloacetate [67]. Yu et al. reported that the elevation of GOT1 expression in pancreatic cancer was associated with shorter overall survival rate [68]. Similarly, Chakrabarti, G. reported that the elevated level of GOT1 in NSCLC resulted in poor outcome after radiotherapy was given, suggesting its involvement in the development of radio-resistance [69]. The same, in this study, GOT1 was up-regulated in cis-resistant cell line as compared to its sensitive A2780 cell line using A2780 ${ }^{\text {cisR }}$ cell line as reference, suggesting GOT1 involvement in the development of drug resistance thus, it can be promising therapeutic and diagnostic tool. Treatment with synergistic combinations of (CS and ART using 0/0 h) partially-restored GOT1 expression. After treatment with synergistic combinations of (CS and OA using 0/0 h), (CS and OA using 0/4 h) and (CS and ART using 4/0 h), GOT1 expression was not detectable, suggesting that GOT1 is highly sensitive towards the treatments. Thus, it may play a major role in the synergistic outcomes, implying a causal relationship between GOT1 expression and drug resistance.

NM23, relatively named as NDKA [15], is considered as metastasis-suppressor [70]. It is involved in large numbers of different biological activities [71], including cell migration, growth control, differentiation and signal transduction [67]. NM23 level was down-regulated in metastasis ovarian carcinoma [72] and nasopharyngeal carcinoma [73]. Likewise, in this study NM23 was down-regulated in A2780 $0^{\text {cisR }}$ cell line as compared to the level found in sensitive A2780 cell line using A2780 cell line as reference, suggesting that down regulation of NM23 plays a role in apoptosis inhibition, pointing out that NM23 expression can be a prognostic marker and therapeutic target. Treatment with synergistic combinations of (CS and ART using 0/0) partially-restored NM23 expression. NM23 expression was not detectable after the treatment with the synergistic combinations of (CS and OA using 0/0 h), (CS and OA using $0 / 4 \mathrm{~h}$ ) and (CS and ART using 4/0 h), suggesting that its expression is strongly sensitive towards the treatments. Thus, the combinations may be beneficial in overcoming drug resistance involving abnormal NM23 expression.

IMMT, also known as Mic60 [74], promotes protein import via (MIA) pathway and regulates cristae morphology and crista junctions [74]. It was down-regulated in prostate cancer androgen-independent (DU145) versus androgen-dependent (LNCaP) cell lines [75]. Similarly, in this study, IMMT expression was decreased in cis-resistant cell line as compared to its sensitive cell line, suggesting its usefulness as biomarker for platinum resistance in ovarian cancer. Treatment with synergistic combinations of (CS and ART using $0 / 0 \mathrm{~h}$ ) and (CS and OA using $0 / 0 \mathrm{~h}$ ) partially restored IMMT expression, suggesting that IMMT may be is playing a role in those synergistic outcomes, given that with the elevation of IMMT expression cell death was increased. Generally, this could be partly attributed to OA and ART actions which adjusted the molecular pathways including increasing Bax, decreasing Bcl-2, up-regulating of the caspases, and down-regulating NF- $\mathrm{KB}$ pathway thereby increased cell sensitivity towards platinum compounds leading to a greater growth inhibition. Therefore, the selected combinations can be a helpful in overcoming drug resistance involved abnormal IMMT expression.

KPYM, also known as PKM2 and PKM [15], catalyses the conversion of phosphoenolpyruvate to pyruvate [76]. It is a member of PK family [77], that plays an essential role in tumour growth and metabolism process [74], through its aerobic glycolysis ability [78,79]. KPYM was down-regulated in gastric carcinoma in cis- resistant cell line versus its sensitive cell line [76] and in colorectal cancer OX-resistant cell line versus its sensitive cell line. However, up-regulation of KPYM was reported in other type of cancers, including multiple myeloma, renal cell carcinoma, pancreatic cancer, ovarian, lung [77], breast, and colon cancer [80,81]. Likewise, KPYM in this study, was up-regulated in cis- resistant cell line versus its sensitive cell line using A2780 $0^{\text {cisR }}$ cell line as reference. The results indicate that KPYM expression is cell and cancer type dependent and its expression is potential diagnostic and therapeutic targets. Treatment with synergistic combinations of (CS and ART using 0/0 h) 
and (CS and OA using 0/0 h) partially-restored KPYM expression. Whereas, after treatment with synergistic combinations of (CS and OA using 0/4 h) and (CS and ART using 4/0 h) KPYM expression was not detectable, implying that KPYM is very sensitive to the indicated combinations, suggesting a strong connection between enhanced apoptosis and KPYM expression.

PSAT, also known and SERC [15], catalyses the formation of 3-phosphoserine from 3 phosphohydroxypyruvate [82], besides its involvement in serine biosynthesis [83]. The elevated expression of PSAT was observed in some cancer types, for example, in colon cancer [83] and clear cell ovarian carcinoma [84]. However, PSAT was not detectable in A2780 cisR cell line as compared to its parental A2780 cell line; this could be attributed to the detection issue or low concentration. After treatment, synergistic combinations of CS and ART (using 4/0 h) and CS and OA (using 0/0 h), PSAT expression was over-restored, suggesting that PSAT may be is participating in the final outcomes where the apoptosis initiation may perhaps be related to improvement of PSAT expression. Thus, the present data may point out PSAT as potential diagnostic and therapeutic targets.

$V D A C 1$, also known as porin 31HM [15], regulates metabolic homeostasis and cell energy [85]. It interacts with antiapoptotic regulators (hexokinase, $\mathrm{Bcl}-\mathrm{Xl}$ and $\mathrm{Bcl}-2$ ). It is involved in releasing apoptotic factors presented in the mitochondria [85]. High level of VDAC1 was observed in various cancers, including cervical, lung, pancreatic, ovarian and thyroid cancers [86]. Likewise, in this study, VDAC1 expression was up-regulated in cis-resistant cell line as compared to parental cell line using $\mathrm{A} 2780^{\mathrm{cisR}}$ as a reference. The findings suggest that the VDAC1 is involved in tumour progression and that it may serve as useful biomarker and therapeutic target. After treatment with synergistic combinations of (CS and ART 4/0 h), (CS and OA using 0/4 h), (CS and ART 0/0 h) and (CS and OA using $0 / 0 \mathrm{~h}$ ) VDAC1 expression was not detectable, suggesting that VDAC1 expression is significantly sensitive to the treatments. The result suggests that the rise in apoptosis could be attributed to a significant down-regulation of VDAC1 expression, suggesting a direct association between them, indicating the effectiveness of the selected treatments in restoring VDAC1 expression towards greater cell kill.

ENOA also known as Enolase 1 [15], is a metabolic enzyme that is implicated in pyruvate synthesis [87]. It facilitates the stimulation of extracellular matrix degradation and plasmin acting as a plasminogen receptor to promote tumour metastasis $[87,88]$. ENOA was elevated in in several malignancies, including breast, brain, gastric, cervix, colon, and kidney [84]. However, in the present study, ENOA was not detectable in the A2780 $0^{\text {cisR }}$ cell line as compared to its sensitive cell line A2780. Similarly, four previous findings from the host laboratory reported the same finding [24,28-30], implying that ENOA is playing a significant role in development of platinum resistance in ovarian cancer. ENOA expression was over/partially-restored due to treatment with the selected combinations. It can thus be suggested that the treatments have inhibited ENOA ability to stimulate extracellular matrix degradation that has enhanced apoptosis induction. In general, therefore, it seems that the enhanced apoptosis could be to some extent ascribed to OA and ART pro-apoptotic ability to down-regulate NF- $\mathrm{KB}$ and Bcl-2 together with their cellular regulatory functions, which in turn has improved cancer cells sensitivity to CS, thereby enhanced apoptosis induction.

VIME is class 3 of intermediate filaments family $[15,89]$. It is associated with tumorigenesis, progression and initiation of cancer [90]. VIME is up-regulated in different type of cancers such as lung, breast, prostate and colorectal [90]. Consistent with the reported findings, VIME was up-regulated in cisplatin-resistant $\mathrm{A} 2780^{\mathrm{cisR}}$ cell line as compared to its sensitive cell line A2780. The results indicate that VIME is playing a major role in cancer progression and reveal that VIME expression can be a valuable marker for various cancers. Treatment with synergistic combinations of (CS and OA using 0/4 h) over-restored its expression in the A2780 cell line. Likewise, treatment with synergistic combinations of (CS and ART using 0/0 h) and (CS and OA using 0/0 h) over-restored the VIME expression. It can thus be suggested that the synergism and observed improve in apoptosis is directly dependent on VIME manifestation. Where the treatments were effective in preventing its cell protection role, given that 
VIME provides resistance against stress and maintains cellular integrity [89]. Therefore, the nominated combinations can serve as useful means to sensitize cancer cells towards CS therapy.

$\mathrm{CAH} 2$ is involved in extracellular acidification [91]. CAH2 was up-regulated in pancreatic and nervous system tumours [92], gastric carcinomas, and brain tumours [93]. In contrast, down regulation of CAH2 was reported in colorectal tumours [92] and hepatocellular carcinoma [93]. In this study, $\mathrm{CAH} 2$ was not expressed in A2780 $0^{\text {cisR }}$ cell line as compared to its sensitive counterpart using A2780 as a reference, which may be due to low concentration or detection problems. Altogether, the findings suggest that the aberrant expression of $\mathrm{CAH} 2$ plays a role in cancer formation, metastasis, and resistance to chemotherapy; thus, it can serve as a promising diagnostic biomarker and therapeutic target. CAH2 expression was extremely sensitive to the treatment with synergistic combinations of (CS and ART using 4/0 h), (CS and OA using 0/4), (CS and ART using 0/0 h) and (CS and OA using 0/0), which might have modulated its acidification regulation activity in response to hypoxic environment leading to decrease cell proliferation that ultimately has increased cell death. Therefore, the results suggest that the restoration of $\mathrm{CAH} 2$ expression can be one of the causal factors for apoptosis induction. Thus, chosen combinations can be effective in combating drug resistance in ovarian cancer involving abnormal CAH2 expression.

VINC is located in cell-adherence junctions and in focal adhesions [94]. It influences adhesion protein turnover and contractility as well as regulates the cell signalling processes [94]. Vinculin may act as a metastasis inhibitor by decreasing cell motility and tumour inhibitor by assisting anchorage-dependent cell growth [94]. In this study, VINC was up-regulated in the cisplatin-resistant A2780 cisR cell line as compared to its sensitive counterpart using A2780 $0^{\text {cisR }}$ cell line a reference, the result suggests the VINC expression as potential therapeutic and diagnostic approaches. Treatment with synergistic combinations of (CS and ART using 0/0 h) and (CS and OA using 0/0 h) partially-restored its expression in $A 2780^{\text {cisR }}$ cell line. Whereas, after treatment with synergistic combinations of (CS and ART using $4 / 0 \mathrm{~h}$ ) and (CS and OA using $0 / 4 \mathrm{~h}$ ) the expression of VINC was not detectable because of the effect of treatments, which by restoring its expression, may be altered protein turnover towards a greater protein degradation thereby enhanced growth inhibition. Hence, the result suggests that the significant reduction in VINC expression can be a causative factor accountable for improved growth inhibition.

GBLP, also known as RACK1 [15], is a cytosolic protein [92,93], which can interact with STAT, tyrosine kinases/phosphatases, PDE4D5, and PKC pathways, involved in cell movement, growth, division and adhesion [95]. GBLP was over-expressed in non-small cell lung cancer, melanoma and hepatocellular carcinoma [95]. In the present study, GBLP was below threshold of detection in the A2780 $0^{\text {cisR }}$ cell line as compared to sensitive A2780 cell line. GBLP expression was over-restored due to the treatment with the selected combinations, suggesting that GBLP restoration is playing a contributory role in enhanced apoptosis resulting from chosen combinations which might have adjusted its behaviour thereby hindered the cell movement cell division towards a batter growth inhibition. It is likely that the significant improve in GBLP expression is directly associated with increased cells receptivity, suggesting GBLP as valuable diagnostic and therapeutic target.

$p 18$, also known as COF1, is a member of COF family [15]. It controls actin dynamics involved in micropinocytosis, chemotactic movement, cell migration, phagocytosis, and proliferation [96]. Over-expression of p18 was reported in radioresistant astrocytomas [97,98], pancreatic cancer versus non-cancerous tissues [96], In this study, however, p18 was down-regulated in cis-resistant cell line as compared to its sensitive counterpart using A2780 as a reference. Although, the result is inconsistent with the reported findings, it can be said that this maker would be promising diagnostic and cancer therapeutic target given its important role in cell movement and propagation. After treatment with synergistic combinations of (CS and ART using 4/0 h) and (CS and OA using 0/4 h) (CS and ART using $0 / 0 \mathrm{~h}$ ) partially-restored p18 expression, suggesting that the observed increase in apoptosis level could be attributed to partial restoration of p18 expression. This may imply that p18 is possibly be involved in development of platinum resistance in ovarian cancer, taken into consideration its vital role as a member of cofilin family. 
EIF5A1, also known as IF5A1 [15], is one isoform of hypusinated eIF5A. It is an essential protein that undergoes many PTM, including acetylation and hypusination [98], which is involved in cell proliferation and the translation elongation stage [99]. EIF5A1 up-regulated in several malignancies, including colorectal carcinoma, lung adenocarcinoma, and glioblastoma [100]; for that reason, EIF5A1 is considered a tumour promoter (oncogene). In this study, EIF5A1 was down-regulated in cis-resistant cell line as compared to the level found in sensitive A2780 cell line. In support of this, Scuoppo et al. reported down-regulation of EIF5A1 in lymphoma [101] and knocking down of EIF5A1 has promoted the tumorigeneses of lymphoma, suggesting it as a tumour suppressor [101]. The findings suggest that EIF5A1 is playing a role in apoptosis inhibition and that its expression is cancer- and cell-type dependent. After treatment, the A2780 $0^{\text {cisR }}$ cell line with synergistic combinations of CS and ART (using 0/0 h) and CS and OA (using 0/0 h) EIF5A1 expression was partially-restored, suggesting that the treatments were able to interrupt its role in protein biosynthesis, thereby prevented translation leading to cell death. Therefore, the results suggest a causal relationship between EIF5A1 expression and platinum resistance in ovarian cancer. Hence, the selected combinations can serve as useful treatments to sensitize cancer cells towards platinum therapy.

EF2 is one member of the elongation group, involved in protein translocation in the elongation stage [98]. EF2 was over-expressed in colorectal and gastric cancers [102], and that was suggested to be due to EF2's ability to stimulate the cell cycle progression at G2/M, cdc2, and Akt, resulting in cell growth enhancement [103]. The result of the present study agrees with the above finding, EF2 was over-expressed in the A2780 ${ }^{\text {cisR }}$ cell line, as compared to the A2780 cell line. The findings, together with the important role of $\mathrm{EF} 2$ in protein biosynthesis, clearly support the idea that elevation of EF2 expression is possibly be involved in ovarian cancer progression and drug resistance. Hence, the results represent EF2 as a new promising diagnosis biomarker and therapeutic target. Treatment, with synergistic combinations of CS and OA (using $0 / 4 \mathrm{~h}$ ) and CS and ART (using 4/0 h) partially-restored EF2 expression. After the treatment with synergistic combination of CS and ART (using 0/0 h) EF2 expression was over-restored. This suggests that the observed rise in apoptosis degree is attributed to improvement of the CS cytotoxic effects by ART and OA actions towards opposing the drug resistance in ovarian cancer, indicating a causal relationship between EF2 expression and platinum resistance in ovarian cancer.

EFTU is another member of the elongation proteins family [15]. It regulates the phosphatidylinositol 4,5 bisphosphate and phosphatidylinositol 4-phosphate levels [100]. EFTU was reported to be up-regulated in the stomach, oesophageal, pancreatic, lung, and renal tumours [104]. In this study, EFTU was not expressed in the A2780 cisR cell line, as compared to its sensitive counterpart, using A2780, was used as a reference, and, consistent with this, Srisomsap et al. reported that EFTU was not expressed in the HepG2 cell line [105] Altogether, the findings indicate that EFTU expression is cancer- and cell type-dependent, suggesting that the EFTU expression can be a potential biomarker and therapeutic target. Treatment with synergistic combinations of CS and OA (using 0/0 h), partially-restored EFTU expression level, while treatment with synergistic combination of CS and ART (using $0 / 0 \mathrm{~h}$ ) over-restored its expression, indicating that the treatment could be an effective way to sensitize cancer calls towards platinum compounds.

EF1G is another member of the elongation proteins. Over-expression of EF1G was observed in gastrointestinal tract malignancies [106], acute myelogenous leukaemia [107], prostate, stomach, colon, lung, and breast cancer [108]. However, it was down-regulated in pancreatic cancers [109]. In this study, EF1G was not detectable (below threshold of detection) in A2780 cisR cell line as compared to the level found in the sensitive A2780 cell line. Taken together, the balance of evidence suggests that the EF1G expression is possibly cancer- or/and cell type -dependent, suggesting that targeting EF1G might be of therapeutic importance. Treatment with synergistic combinations of CS and ART 9using 0/0 h) and CS and ART (4/0 h) partially-restored EF1G expression, whereas, synergistic combination of $\mathrm{CS}$ and OA (using 0/4 h) over-restored its expression, suggesting that the restoration of EF1G by the treatments might have inhibited transformation by preventing translation of proteins during protein biosynthesis that have a direct role on cell growth reduction. Hence, EF1G expression may be is 
directly participating in the synergistic outcomes resulting from the combination of CS with OA and ART, where the improved apoptosis could be directly linked to EF1G restoration. Thus, selected combinations are effective in improving cancer cell sensitivity towards platinum drugs involved EF1G irregular expression.

EF1A1 is the other member of this group, involved in protein synthesis during elongation stage [110], which is also known as EEF1A1 [15]. EF1A1 is associated with binding of G-actin, binding of microtubules, bundling of F-actin, and transporting $\beta$-actin mRNA [110]. It is over-expressed in pancreatic melanoma, lung, breast, colon, and prostate tumours [111]. Consistent with the reported findings, in the present study EF1A1 was up-regulated in A2780 ${ }^{\text {cisR }}$ cell line as compared to its sensitive counterpart A2780. The findings suggest that EF1A1 plays an important role in apoptosis inhibition and development of drug resistance. After treatment with synergistic combinations of CS and OA (using 0/4 h) and CS and ART (using 0/0 h) EF1A1 expression was over-restored. While treatment with synergistic combination of (CS and OA using $0 / 0 \mathrm{~h}$ ) partially-restored its expression, suggesting a straightforward connection between the elevated growth inhibition and decreased EF1A1 expression. This clearly supports that targeting EF1A1 can be a promising means to increase cancer cells sensitivity towards platinum drugs. Hence, selected treatments can serve as alternative approaches to overcome Pt-resistance through improving EF1A1 expression.

hnRNPA1, belong to mRNA processing proteins, which plays fundamental functions in gene expression regulation at translational and transcriptional levels [111], also are implicated in cell signalling, telomere biogenesis, and DNA repair [111]. hnRNPA1, also known as ROA1 [15], is up-regulated in a large number of cancers such as colorectal, breast, gliomas, and lung [112]. Similarly, in this study, hnRNPA1 was up-regulated in A2780 cisR cell line as compared to the level found in A2780 cells when A2780 was used as a reference, indicating that hnRNPA1 can be useful cancer biomarker and therapeutic target. Treatment of with synergistic combinations of CS and ART (using 0/0) and CS and OA (using 0/0) over-restored its expression. While after treatment with combinations of CS and ART (using 4/0) and CS and OA (using 0/4) hnRNPA1 expression was not detectable. Hence, the result suggests that the selected combinations have affected hnRNPA1 actions in gene expression and DNA repair, thereby increased cells vulnerability to CS cytotoxic action, leading to a better cell kill.

hnRNPA2/B1, also known as ROA2 [15], is another protein belongs to this group. It involves in various functions, including the regulation of mRNA metabolism, translation and transcription [113]. Up-regulated in serval cancer types such as pancreatic, lung [114], and breast [115]. Likewise, hnRNPA2/B1 was up-regulated in the cis-resistant cell line as compared to the level found in sensitive A2780 cell line. Altogether, the findings indicate its therapeutic value as diagnostic and medicinal target. It is worth noting that, in this study, hnRNPA2/B1 was named by MS for three spots (16 and 76 when A2780 was used as reference spot 18 when was $A 2780^{\text {cisR }}$ when used as a reference). After treatment with selected combinations, hnRNPA2/B1 expression was partially and over-restored, suggesting that the restoration of hnRNPA2/B1 expression possibly has altered its translation and transcription action, and, thereby, increased cell death. Hence, the result supports the possibility of a causal relationship between hnRNPA2/B1 expression and the resistance in ovarian caused by CS treatment.

PGK1 is participating in the glycolytic pathway and contributing in angiogenesis events [116]. PGK1 was up-regulated in various cancers, such as multi-drug resistant ovarian cancer, breast cancer, renal cancer, pancreatic carcinoma, and squamous cell carcinoma [117-119]. Similarly, in the present study, PGK1 was up-regulated in A2780 $0^{\text {cisR }}$ cells as compared to the level found in sensitive A2780 cell line when $\mathrm{A} 2780^{\mathrm{cisR}}$ was used as a reference. Thus, it can be said that PGK1 and its signalling genes can serve as future prognostic markers. Treatment with synergic combinations of CS and ART (using 0/0 h), CS and ART (using 4/0 h), and CS and OA (using 0/4 h) partially-restored PGK1 expression, suggesting the treatments might have influenced PGK1 angiogenic function, thereby preventing nutrients and oxygen, leading to a greater cell kill. However, its expression was further up-regulated due to the 
treatment with synergistic combination of $\mathrm{CS}$ and $\mathrm{OA}$ (using $0 / 0 \mathrm{~h}$ ). From the above findings, it remains difficult to clearly establish clear association between PGK1 expression and enhanced cell kill and synergistic outcome. Hence, further studies would be necessary to gain better insight.

PRDX1, also known as PAG [15], is an antioxidant [120]. Its function interchanges from (peroxidase to a chaperone) with a high level of hydrogen peroxide [120]. Up-regulated level of PRDX1 was found in lung ovarian, liver, breast, gallbladder, prostate, and bladder cancer [120]. In this study, PRDX1 was below threshold of detection in cisplatin-resistant A2780 cisR cells as compared to the level found in A2780 cells when A2780 was used as a reference. However, Ren, Ye et al. reported a "relatively weak expression" of PRX1 in laryngeal cancer (Hep2), liver cancer cell (SUN449) lymphoma leukaemia (KOPN63) and acute lymphoblastic leukaemia (MOLT-4) cell lines [117]. The discrepancies, a result of unknown effect of PRDX1 or/ and its interchangeable role between peroxidase and chaperone functions. However, it can be said that PRX1 expression is cell, stage and cancer type dependent, suggesting a potential role of PRDX1 as therapeutic target and useful biomarker. Treatment with synergistic combinations of CS and OA (using 0/4 h) and CS and ART (using 4/0 h) partially-restored PRDX1 expression, while treatment with synergistic combinations of CS and OA (using 0/0 h) and CS and OA (using 0/0 h) over-restored PRDX1 expression, suggesting that the chosen combinations have repressed its antioxidant effect and enhanced its chaperone action towards a greater rate of growth inhibition. Thus, the result suggests a direct association between PRDX1 expression and apoptosis induction. Hence, the nominated combinations are beneficial in overcoming drug resistance in ovarian cancer involved abnormal expression of PRDX1.

PRDX6, also known as 1-Cys PRX, is a bifunctional enzyme [121] where it has a phospholipase A2 and glutathione peroxidase activities [121]. It is involved in tumour metastasis, proliferation and protection [121], playing both anti cytoprotective or cytoprotective roles [122]. PRDX6 was up-regulated in various cancers such as breast [121], lung [122], and oesophageal cancer [64]. In the present study, PRDX6 was below threshold of detection, in the A2780 $0^{\text {cisR }}$ cell line as compared to the level found in A2780 cells when A2780 was used as a reference, however, RDX6 was very sensitive to selected treatments, suggesting a direct association between promotion of apoptosis and PRDX6 level of expression. Given its bifunctionality, it is possible that targeting PRDX6 might be of therapeutic importance.

Op18, also known as STMN1 [15], is a highly conserved phosphoprotein involved in cell proliferation, morphogenesis, and differentiation [123]. It plays a role in the regulation of the microtubule filament system through microtubules destabilization [15]. Fang et al. reported that Op18 was over-expressed in different cancers, including osteosarcoma, lung, breast, and bladder [124]. In contrast, in this study, Op18 was down-regulated in cisplatin-resistant A2780 $0^{\text {cisR }}$ cells as compared to its sensitive counterpart using A2780 as a reference. However, the result is in line with previous findings from the host laboratory using the same cell lines [24,28], suggesting that Op18 expression is a cell- and cancer type-dependent. Despite these discrepancies, it can be said that Op18 can serve as a potential biomarker for the resistance in ovarian cancer. Treatment with synergistic combination of (CS and ART using 0/0 h) over-restored Op18 expression, suggesting the selected treatment may have disturbed its morphogenetic signalling preventing cell proliferation that in turn led to growth inhibition, indicating that treatment could be an effective means to sensitize cancer calls towards cisplatin.

MCM7, also known as CDC47 [15], is a member of the MCM complex [125] involved in the regulation of cell cycle progression and licensing DNA replication [126]. MCM7 was over-expressed in different human cancers, including neuroblastoma, colorectal and prostate [127]. In this study, MCM7 was not detected in A2780 ${ }^{\text {cisR }}$ cell line as compared to the level found in sensitive A2780 cell line. Treatment with the synergistic combinations of CS and OA (using $0 / 0 \mathrm{~h}$ ) over-expressed MCM7 expression. While treatment with the combination of CS and ART (using $0 / 0 \mathrm{~h}$ ) fully-restored its expression. This could be partially attributed to ART inhibitory ability of the important cell cycle regulators, including CDK4, CDK2 [13], cyclin A, cyclin E, cyclin D3, cyclin D1, CDK6, and E2F1 [17], given that MC7 is associated with cell cycle regulation, it is possible that ART was able to recover MCM7 
expression as a one of the cell cycle regulators proteins, which in turn have improved CS cytotoxic action. Therefore, the results suggest a direct correlation between improved cell death and MCM7 expression and indicate that the selected combinations are valuable in opposing of $\mathrm{Pt}$ resistance in ovarian cancer.

CLIC1, also known as NCC27 [15] is one of CLIC family which involved in the regulation of trans-epithelial transport, cell volume, electrical excitability, $\mathrm{pH}$ levels, ion homeostasis, cell adhesion, cells apoptosis and cell cycle [55]. In the present study, CLIC1 was down-regulated in cisplatin-resistant cell line as compared to the level found in the sensitive A2780 cell line when the A2780 $0^{\text {cisR }}$ cell line was used as a reference. Treatment with synergistic combination of CS and ART (using 0/0 h) over-restored its expression, whereas, treatment with synergistic combination of CS and OA (using 0/0 h) further down-regulated CLIC1 expression. These obviously confusing findings suggest that CLIC1 may possibly not be playing any important role in those outcomes. However, taken into consideration CLIC1's roles in chloride channel [128], cell adhesion, cells apoptosis, and cell cycle [61], suggesting that targeting CLIC1 might be of therapeutic importance. Additional studies at a molecular level would be required to clarify the matter.

RAN is a member of the Ras super-family [125], also known as GTPase Ran [15]. It promotes the assembly of bipolar spindle in mitosis phase [129]. The elevated level of RAN was reported in different cancers such as ovarian, stomach, kidney, colon, and lung cancer [125]. Similarly, in this study, RAN was up-regulated in cis-resistant cell line as compared to its sensitive counterpart using A2780 cisR cell line as reference. Silencing of RAN inhibited cell growth, or/and induced apoptosis in colon, nasopharyngeal, renal breast, and ovarian tumours [128]. The findings suggest that RAN expression is a promising diagnostic marker and therapeutic target. Treatment with synergistic combination of CS and ART (using 4/0 h) over-restored RAN expression, whereas, treatment with synergistic combinations of CS and OA (using 0/4 h), CS and ART (using 0/0 h), and CS and OA (using 0/0 h) partially-restored its expression, suggesting the treatments have suppressed RAN activity of bipolar spindle assembly in mitosis phase leading to a greater growth inhibition. Therefore, the results indicate that the reduction in RAN expression can be directly accountable for the observed rise in cell kill. Hence, the selected treatments can be a potential therapeutic strategy to sensitize ovarian cancer cells towards Pt drugs.

Moreover, $1433 \mathrm{Z}$ is another signal transduction protein, it is one isoform of the 14-3-3 family, which exhibits a pro-oncogenic role in multiple tumour types [130]. The 1433Z is the key regulator of the major cellular processes [131], including autophagy, progression, adhesion, differentiation, proliferation, and apoptosis [131]. The 1433Z was down-regulated in A2780 cisR cells as compared to its sensitive counterpart, when A2780 was used as reference. Likewise, previous findings reported down-regulation of $1433 \mathrm{Z}$ in (A2780-TR, TA) paclitaxel-resistant as compared to its sensitive counterpart [132], and in (SKOV3-TR, TS) as compared to its sensitive counterpart [132]. However, up-regulation of $1433 \mathrm{Z}$ expression was reported with others cancers such as pancreatic [131], head and neck, NSCLC, breast [127], hepatocellular carcinoma, and stomach cancer [133]. Overall, the results indicate that $1433 \mathrm{Z}$ expression is cancer and cell dependent, suggesting that the level of its expression is a potential diagnostic marker for Pt-drug resistance in ovarian cancer, Treatment with synergistic combinations of CS and ART (using 0/0 h) and CS and OA (using 0/0 h) over-restored 1433Z expression, while treatment with synergistic combination of (CS and OA using $0 / 4 \mathrm{~h}$ ) partially-restored its expression, suggesting that the growth inhibition produced by the combination of OA and ART with CS, was caused by the down-regulation of Bcl-2 and NF- $\mathrm{KB}$ mediated by other mechanisms. For example, in the case of the combination with ART the final outcomes could be ascribed to the inhibition of cyclin A, cyclin E, cyclin D3, cyclin D1, CDK6, E2F1 and JAB1 transcriptions [17], CDK4, CDK2 expressions [13], S6K, PI3K, mTOR, Akt [10] and enhancement of IFIT3, p21, and p27 [17]. This has increased the influx of CS or/and decreased its efflux. Additionally, the selected combinations might have manipulated $1433 Z$ effect on cell adhesion, cell differentiation, and cell proliferation, which in turn has prompted apoptosis induction. Thus, the results overall suggest that the selected combinations are beneficial for $1433 \mathrm{Z}$ restoration towards overcoming drug resistance in ovarian cancer. 
Two subunits of proteasome PSA3and PSA7 were also found to be differentially expressed, are involved in the regulation of several crucial cellular process, including apoptosis, immune responses, DNA repair, protein quality control and cell cycle progression [134]. PSA3 (also known as PSMA3) [15], was down-regulated in cis-resistant cell line as compared to its sensitive counterpart when A2780 was used as a reference, this is consistent with finding of Moghanibashi et al. in which PSA3 was reported to be down-regulated in ESCC [135]. PSA7, also known as PSMA7 [15]. It was up-regulated in cis-resistant cell line as compared to its sensitive counterpart when A2780 cisR cell line was used as a reference. Up-regulation of PSA7 expression was reported previously in colorectal cancer [136]. The results suggest that PSA3 and PSA7 may serve as potential diagnostic and therapeutic targets. PSA3 and PSA7 expressions after treatment with selected combinations were either partially or over-restored, suggesting that the treatments may be have decreased PSA3 and PSA7 DNA repair ability and recovered their growth inhibition ability that have increased the cell cycle arrest and decreased protein quality control leading to a greater growth inhibition. Hence, the result suggests a causal relationship between PSA3 and PSA7 expressions and resistance to cisplatin therapy, signifying the effectiveness of the applied treatments in overcoming drug resistance involved abnormal PSA3 or/and PSA7 expression in ovarian cancer.

\section{Materials and Methods}

CS, OA, ART, trypsin, HEPES, triton-X 100, PBS, MTT, DMSO, and NaOH (Sigma-Aldrich, Castle Hill, Australia), $\mathrm{K}_{2}\left[\mathrm{PtCl}_{4}\right]$ (Sigma, USA), KI (BDH Chemicals, Queensland, Australia), A2780, A2780 cisR and A2780 ZD0473R ovarian cancer cell lines were kindly provided by Dr Philip Beale (NSW Cancer Centre, Royal Prince Alfred Hospital (RPAH), Sydney, Australia), Varian Cary 1E UV/VIS spectrophotometer, Varian SpectrAA240 atomic absorption (AAS) with GTA-120 graphite furnace tube atomizer at the host laboratory (School of Medical Sciences, The University of Sydney), 28\% ammonia solution (UNIVAR, Downers Grove, IL, USA), $\mathrm{AgNO}_{3}$ (BDH Chemicals), FCS, 5× RPMI1640 media, L-glutamine, and $\mathrm{NaHCO}_{3}(5.6 \%)$ (Thermo Trace Pty Ltd. Melbourne, Australia), $25 \mathrm{~cm}^{2}$ cell culture flasks (Crown Scientific, San Antonio, TX, USA), carbon dioxide incubator (SANYO, Osaka, Japan), JETQUICK DNA Spin Kit (GENOMED GmbH, Löhne, Germany), Tris (hydroxymethyl) aminomethane hydrochloride (Sigma, Munich, Germany), CalcuSyn software version 2 (Bio-Rad,Cambridge, UK), urea and CHAPS (Calbiochem, Darmstadt, Germany), thiourea and DTT (Merck, Darmstadt, Germany). Melanie version 7.0 (SIB, GeneBio, Geneva, Switzerland). glycerol and SDS (MP Biomedicals, LLC, Illkirch Cedex, France), DeStreak reagent (GE Healthcare Bio-sciences AB, Uppsala, Sweden), criterion TGX Precast gel, iodoacetamide, carrier ampholytes, PROTEAN i12 IEF system, mineral oil, and $10 \mathrm{X}$ tris/glycine buffer (Bio-Rad, Irvine, CA, USA), agarose, wicks, ChemiDoc XRS imaging system, Bio-Safe Coomassie Stain, Ready-Strip ${ }^{\mathrm{TM}}$ IPG Strip, criterion Dodeca cell, protein assay standard II kit, bromophenol blue, Microplate Reader Model 3550, and automated cell counter (Bio-Rad, Gladesville, Australia) 96 well flat bottom plates (Edward Keller), and $\mathrm{KCl}$ (BDH Chemicals).

\subsection{Cell Culture and Subculture}

Cell culturing was carried out following the same procedure as described previously [137]. Briefly, cells were grown in flasks $25 \mathrm{~cm}^{2}$, incubated in $95 \%$ air, $5 \% \mathrm{CO}_{2}$ at $37^{\circ} \mathrm{C}$. Cells were preserved in (log) growth phase in RPMI 1640 containing heat-inactivated fetal calf serum $(10 \%)$, bicarbonate $(0.112 \%)$, HEPES (20 mM), and glutamine ( $2 \mathrm{mM})$. A2780 cell line was subjected to increasing intensity of CS until it gained resistant (A2780 $0^{\mathrm{cisR}}$ ). Moreover, A2780 cell line was treated continuously with increasing strengths of ZD0473 to develop resistant to the drug [136].

\subsection{Drugs Preparation}

Cisplatin was dissolved in dimethyl formamide (DMF) followed by addition of Milli-Q water (at the ratio of 1:5) to give $1 \mathrm{mM}$ stock solution. Oleanolic acid (OA) was dissolved in ethanol to attain 
$1 \mathrm{mM}$ concentration. Artemisinin (ART) was dissolved in ethanol and Milli-Q (mQ) water (at a ratio 50:50) to attain $1 \mathrm{mM}$ concentration.

\subsection{Single-Drug Treatments}

Stock solutions were subjected to serial dilutions to give final concentrations ranging from 0.16 to $200 \mu \mathrm{M}$, using 10\% RPMI1640 medium. Cells at a density of 4000 to 6000 cells/well were treated with CS, OA, and ART, individually at four different concentrations, repeated three times in the same plate, and incubated for $72 \mathrm{~h}$. Two controls were used; one contained cell and medium and the other contained (cells, medium and ethanol). Cytotoxic effects of CS, OA, and ART alone at different concentrations were evaluated using MTT assay following the procedure described by Mosmann [137]. Briefly, after $72 \mathrm{~h}$ of incubation with drug(s), medium was replaced by adding fifty $\mu \mathrm{L}$ of MTT solution to each well followed by further $4 \mathrm{~h}$ incubation. Then one hundred fifty $\mu \mathrm{L}$ of DMSO was added to each well to dissolve formazan crystals after MTT solution was aspirated. The absorbance at $570 \mathrm{~nm}$ was measured using microplate reader [137]. Percentage of living cells was calculated by dividing the average of optical density of wells (containing treated cells) by the average of optical density of wells (containing untreated cells). Concentration of (CS, OA, or ART) required to produce $50 \%$ of growth inhibition in each cell line compared to control (which is referred to as $\mathrm{IC}_{50}$ value) was obtained from the standard curve, representing the percentage of the cell viability versus the concentration.

\subsection{Combination Studies}

Cells were treated with solutions of compounds alone and in combination at three different concentrations, generally at constant ratios of their $\mathrm{IC}_{50}$ values. The concentration ranges were: cisplatin: $0.13-2.11 \mu \mathrm{M}, 1.29-20.61 \mu \mathrm{M}$ and $1.67-26.78 \mu \mathrm{M}$; oleanolic acid: $6.80-108.80 \mu \mathrm{M}, 5.23-83.68 \mu \mathrm{M}$, and 2.17-34.72 $\mu \mathrm{M}$; artemisinin 3.36-53.70 mM, 5.36-85.76 mM, and 7.27-116.35 mM for A2780 (parent), A2780 ${ }^{\text {cisR }}$ (cisplatin resistant) and A2780 ZD0473R (ZD0473-resistant) cell lines respectively. Briefly, $100 \mu \mathrm{L}$ of cells seeded in each well of 96-well plate were treated with CS, OA, and ART alone and in combination with CS using the chosen concentrations, following three sequential modes; (Pt/Phyt: 0,0 h), (Pt/Phyt: 0/4 h) and (Pt/Phyt: 4/0 h), non-treated cells served as control. The plates were incubated for $72 \mathrm{~h}$ with each experiment repeated three times. The inhibition of cell growth was determined using the (MTT) reduction assay as previously mentioned. The combination index (CI) value of two compounds in combination was determined according to the method developed by Chou and Talalay [14]. $\mathrm{CI}$ of $<1,=1$ and $>1$, indicates synergism, additiveness, and antagonism respectively [14,138].

\subsection{Platinum Cellular Accumulation and Platinum DNA Binding Studies}

A2780 and A2780 cisR cells with density of $\left(5 \times 10^{6} \mathrm{~mL}^{-1}\right)$ in each petri dish treated with CS alone and its binary combinations with OA and ART using fixed concentrations of their $\mathrm{IC}_{50}$ values, were incubated for forty-eight hours. Cells were collected and centrifuged at $3500 \mathrm{rpm}$ for two minutes at $4{ }^{\circ} \mathrm{C}$. Next, cell pellets were washed twice with $4 \mathrm{~mL}$ of cold PBS and centrifuged at $3500 \mathrm{rpm}$ at $4{ }^{\circ} \mathrm{C}$ for two minutes. Cell pellets were then re-suspended with $0.5 \mathrm{~mL}$ of cold PBS. Then $(1.5 \mu \mathrm{L})$ was taken from each sample and mixed with the same quantity of trypan blue to determine the cell survival fraction using the automated cell counter. The samples were then re-spun for two minutes at $10,000 \mathrm{rpm}$ at $4{ }^{\circ} \mathrm{C}$ then cell pellets were stored at $-20^{\circ} \mathrm{C}$ until assayed.

\subsection{Cellular Accumulation}

Cell pallets were lysed with $0.5 \mathrm{~mL}$ of $1 \%$ triton-X100 added to each sample and sonicated in ice for thirty minutes then centrifuged at 14,000 rpm for three minutes. Then $400 \mu \mathrm{L}$ of the supernatant from each sample was used to determine cellular platinum levels by measuring the absorbance values using graphite furnace atomic absorption spectrometry. The platinum level in each sample was calculated as nmol of platinum per $5 \times 10^{6}$ cells. 


\subsection{Platinum-DNA Binding}

Cell pellet from each sample was re-suspended in $200 \mu \mathrm{L}$ of PBS for DNA extraction using JETQUICK DNA Spin Kit following the protocol of the provider's instructions (see ref, [139]. The DNA content was calculated from absorbance as A260 $\mathrm{nm} \times 50 \mathrm{ng} / \mu \mathrm{L}$ [140]. A260/A280 ratio [140] between 1.75 and 1.8 for each sample ensured acceptable purity for tested samples. Next, $200 \mu \mathrm{L}$ from each DNA sample was used for platinum level quantification using graphite furnace AAS.

\subsection{Proteomic Studies}

The proteomic studies were initially intended: (1) to determine the proteins that underwent changes in expression in A2780 cisR as compared to parent A2780 cell line and (2) to evaluate the effect of the selected combination treatments on those proteins. The studies were based on 2-D gel electrophoresis and the use of Melanie 7.0 software. The ultimate objective was to identify protein biomarkers that might be associated with the resistance towards CS, using MALDI TOF/TOF MS/MS. The identified spots were matched against Mascot (http://www.matrixscience.com), Swiss-Prot database (http://www.uniprot.org/), at APAF (http://www.proteome.org.au/). "This work was undertaken at APAF the infrastructure provided by the Australian Government through the National Collaborative Research Infrastructure Strategy (NCRIS)."

\subsection{Sample Preparation, Treatments, Pellet Collection and Protein Quantification}

A2780/ A2780 cisR $\left(5 \times 10^{4}\right)$ cells were seeded and incubated for $24 \mathrm{~h}$. The next day, A2780 $0^{\text {cisR }}$ cells were treated with chosen drug combinations, namely CS and ART (using 4/0 h), CS and OA (using 0/4 h), CS and ART (using 0/0 h), and CS and OA (using 0/0 h); then all samples (including untreated samples from both cell lines) were incubated for $24 \mathrm{~h}$. Cells then were collected, centrifuged (at $3500 \mathrm{rpm}, 2 \mathrm{~min}$ at $4{ }^{\circ} \mathrm{C}$ ), washed (PBS/5 mL), re-suspend (by PBS/ $1 \mathrm{~mL}$ ), counted, and centrifuged (at $14000 \mathrm{rpm}, 2 \mathrm{~min}$ at $\left.4{ }^{\circ} \mathrm{C}\right)$. Following this, the pellets were lysed in $500 \mu \mathrm{L}$ of: $(501 \mu \mathrm{L})$ of $65 \mathrm{mM}$ DTT, $(24.04 \mathrm{~g})$ of $8 \mathrm{M}$ Urea, $(2.00 \mathrm{~g})$ of $4 \%$ CHAPS, $(7.61 \mathrm{~g}$ ) of $2 \mathrm{M}$ thiourea, (5 tablets) protease inhibitor and (up to $50 \mathrm{~mL}$ ) of $\mathrm{mQ}$ water. Subsequently, the pellets were lysed and centrifuged at $\left(13,000 \mathrm{rpm}\right.$ and $\left.4{ }^{\circ} \mathrm{C}\right)$ for thirty minutes. Next, the supernatant was collected and stored at $-80^{\circ} \mathrm{C}$ (see refs [141]. Total protein was measured as described by the assay kit provider [142], based on Bradford method [143]. The absorbance was measured at $595 \mathrm{~nm}$ using microplate reader BIO-RAD Model 3550. The standard curve was used to determine protein concentration of the samples.

\subsection{Two-Dimensional Gel Electrophoresis}

For protein separation, first-dimension IEF was performed following the technique of the provider's manual * [144]. These Bio-Rad manuals do not have author or published dates; therefore, $\left({ }^{*}, * *\right.$ and $\left.{ }^{* *}\right)$ was placed next to the reference to distinguish each instruction manual. However, the URL of each one is provided at the reference list. Moreover, they can be found at the company's website (https://www.bio-rad.com/) through their distinct bulletin numbers (bulletin \#4110009, bulletin \#2651, and bulletin \#4006197). Briefly, the IPG strip (11 cm L×3.3 mm W $\times 0.5 \mathrm{~mm}$ thick/3-10 NL pH gradient) was passively rehydrated in $180 \mu \mathrm{L}$ of rehydration solution containing: $4 \%$ CHAPS $100 \mu \mathrm{L}, 0.0002 \%$ bromophenol blue, $60 \mathrm{mM}$ DTT, 8 M Urea, (15 mg/ $1 \mathrm{~mL})$ DeStreak, $2 \mathrm{M}$ thiourea, and $0.2 \%$ ampholytes with $200 \mu \mathrm{g}$ of protein from each sample then the samples were kept overnight. Then IEF procedure was performed using PROTEAN i12 IEF system following the manufacturer's running protocol ${ }^{* *}$ [145]. The 2nd dimension was carried out using IPG strip, precast gels and criterion Dodeca cell unit, following the procedures described in the product's instruction manual *** [146]. Briefly, IPG strips were incubated in (traces of bromophenol, $20 \%$ glycerol $v / v$, $2 \%$ DTT $w / v, 50 \mathrm{mM}$ Tris- $\mathrm{HCl} \mathrm{pH} 8.8,2 \% \mathrm{SDS} w / v$, and $6 \mathrm{M}$ urea) then were kept on a rocker for fifteen minutes ${ }^{* *}$ [145] Again, the strips were incubated in (traces of bromophenol, $2 \%$ glycerol $v / v, 50 \mathrm{mM}$ Tris- $\mathrm{HCl} \mathrm{pH} 8.8,2 \%$ SDS $w / v, 2 \%$ IAA $w / v$, and $\mathrm{M}$ urea) solution and left on a rocker 
for fifteen minutes ** [145]. Next, IPG strips were washed with (192 mM glycine, $0.1 \%(w / v)$ SDS, $\mathrm{pH}$ 8.3, and $25 \mathrm{mM}$ Tris). The Criterion Dodeca Cell was filled with $6 \mathrm{~L}$ of $(6 \mathrm{X})$ Tris/Glycine/SDS (0.1\% SDS, $192 \mathrm{mM}$ glycine, and $25 \mathrm{mM}$ tris, $\mathrm{pH}$ (8.3). Before running the program, gel cassettes were sealed with a melted agarose ${ }^{* *}$ [145]. Sequentially, the unit was run for sixty-five minutes at $200 \mathrm{~V} * * *$ [146]. The gels were dyed with Coomassie blue, scanned with the ChemiDoc XRS imaging system and saved as TIFF format (see, [147]. The paired gel images (12 gels, a duplicate for each gel sample) from untreated A2780 cell line, untreated A2780 ${ }^{\text {cisR }}$ cell line, treated A2780 cisR cell with the following combinations: CS and ART (using 4/0 h), CS and OA (using 0/4 h) and CS and ART (using 0/0 h) and CS and OA (using 0/0 h), and were imported into Melanie 7.0 software and clustered into six groups for spots detection and quantification, following the product's manual instructions (see, [148]. Briefly, the spot from the same sample was manually and automatically matched and paired using two landmarks. Next, the matched spots were annotated and assigned identical matched ID in all gel samples. Following this, the six groups were assembled into four hierarchical classes: (1) untreated A2780, (2) untreated A2780 ${ }^{\text {cisR }}$, (3) treated A2780 $0^{\text {cisR }}$ with (CS and OA), and (4) treated $\mathrm{A} 2780^{\mathrm{cisR}}$ with (CS and ART), subsequently, spots were automatically analysed and compared across all the samples using A2780 cell line as a reference after that untreated $\mathrm{A} 2780^{\mathrm{cisR}}$ cell line as reference then spots were quantified automatically. In this study, a two-fold or greater change in protein expression was considered significant. Based on this parameter, 101 spots out of 133 spots were selected and sent to APAF (Macquarie University) for protein identification using MALDI-TOF and Mass Spectroscopy through APAF (http://www.proteome.org.au/). The detailed methods of MALDI and MS were previously described [149-151]. Briefly, at APAF (Macquarie University) (http://www.proteome.org.au/), using 4800 plus MALDI TOF/TOF Analyser (AB Sciex), spots were excised (spot cutter/ Bio-Rad), de-stained (ammonium bicarbonate / acetonitrile) and digested (ammonium bicarbonate, $16 \mathrm{~h}$ at $37^{\circ} \mathrm{C}$ ). Next, the peptides were extracted (0.1\% TFA/C18 zip-tip) and yield (MALDI-MS). The most intense (8) peptide peaks (ions) from each spot were further fragmented by (CID system). Masses and intensities were measured by MS/MS (TOF-TOF) and matched against Mascot database (Matrix Science Ltd., London, UK). (http://www.matrixscience.com/). Monoisotopic peak lists were matched against Homo sapiens using Swiss-Prot database (http://www.uniprot.org/) [15]. The score was calculated according to Mascot parameter (http://www.matrixscience.com/) and as previously reported (greater than 56 is significant, $p<0.05)$.

\section{Conclusions}

The results show that synergistic effect from combinations of CS with OA and ART in A2780, $\mathrm{A} 2780^{\mathrm{cisR}}$, and $\mathrm{A} 2780^{\mathrm{ZD} 0473 \mathrm{R}}$ are dependent on the dose, time, and cell type. The results show that the increased CS-DNA binding levels was consistent with the observed increase in CS-accumulation. The results also show that platinum-DNA levels are greater in the A2780 ${ }^{\text {cisR }}$ cells, indicating that the presence of ART and OA have modulated some of the platinum resistance mechanisms, such as decreases of the platinum-DNA adducts formation [18], increases of platinum detoxification, and increases of DNA repair [19].

Investigation of proteins expression has shown that out of 101 proteins, (49) proteins were $2 \geq$ fold differently expressed and were successfully identified by MS. Those proteins were shown to play a critical role in cell cycle regulation, pro-survival, and anti-survival pathways, suggesting their participation in platinum drug resistance. Most of the identified proteins are associated with molecular chaperones and stress, metabolism, and invasion and metastasis. It can, thus, be suggested that those identified proteins can be additional novel predictive factors for early detection to individualised therapeutic interventions, considering the differences of each histologic type to improve the overall survival rate along with preserving the quality of the patient life. Finally, this study suggests that these synergistic combinations were able to restore back most of the protein expressions in the A2780 ${ }^{\text {cisR }}$ cell line; thus, they can be deemed as valuable approaches to circumvent Pt-resistance associated with aberrant expression of those proteins in ovarian cancer. Based on this study, evaluations of cellular 
sensitivity/resistance to those treatments in vivo studies using suitable animal models deserve to be further tested in the future. Studies on cellular DNA damage, oxidative stress, and cell cycles may provide further mechanistic information.

Supplementary Materials: The following are available online at http://www.mdpi.com/1422-0067/21/20/7500/s1, Table S1, Video S1: Characteristics of proteins that have undergone differential expressions in A2780 and A2780cisR cell lines following treatment with selected drug combinations using A2780 cell line as reference.

Author Contributions: S.I.A. developed the methodology, acquired, and interpreted data, and drafted the manuscript. P.B. and J.Q.Y. aided in study design. F.H. conceived and designed the study, developed the methodology, edited the manuscript, and oversaw the study. All authors have read and agreed to the published version of the manuscript.

Funding: This research received no external funding.

Acknowledgments: S.I.A. is grateful to the Saudi Government for the award of a PhD scholarship. This research is partly supported by the Biomedical Science Research Initiative Grant and Cancer Research Donation Fund. Part of the proteomic work was undertaken at APAF, the Infrastructure provided by the Australian Government through the National Collaborative Research Infrastructure Strategy (NCRIS).

Conflicts of Interest: The authors declare no conflict of interest.

\section{References}

1. Nowak, M.; Glowacka, E.; Kielbik, M.; Kulig, A.; Sulowska, Z.; Klink, M. Secretion of cytokines and heat shock protein (HspA1A) by ovarian cancer cells depending on the tumor type and stage of disease. Cytokine 2017, 89, 136-142. [CrossRef] [PubMed]

2. Hacker, N.F.; Rao, A. Surgery for advanced epithelial ovarian cancer. Best Pract. Res. Clin. Obstet. Gynaecol. 2017, 41, 71-87. [CrossRef] [PubMed]

3. Aletti, G.D.; Peiretti, M. Quality control in ovarian cancer surgery. Best Pract. Res. Clin. Obstet. Gynaecol. 2017, 41, 96-107. [CrossRef] [PubMed]

4. Florea, A.M.; Büsselberg, D. Cisplatin as an anti-tumor drug: Cellular mechanisms of activity, drug resistance and induced side effects. Cancers 2011, 3, 1351-1371. [CrossRef]

5. Sarkar, F.H.; Li, Y. Using chemopreventive agents to enhance the efficacy of cancer therapy. Cancer Res. 2006, 66, 3347-3350. [CrossRef]

6. Amable, L. Cisplatin resistance and opportunities for precision medicine. Pharmacol. Res. 2016, 106, 27-36. [CrossRef]

7. Ohmichi, M.; Hayakawa, J.; Tasaka, K.; Kurachi, H.; Murata, Y. Mechanisms of platinum drug resistance. Trends Pharmacol. Sci. 2005, 26, 113-116. [CrossRef]

8. Apps, M.G.; Choi, E.H.; Wheate, N.J. The state-of-play and future of platinum drugs. Endocr. Relat. Cancer 2015, 22, R219-R233. [CrossRef]

9. Pollier, J.; Goossens, A. Oleanolic acid. Phytochemistry 2012, 77, 10-15. [CrossRef]

10. Žiberna, L.; Šamec, D.; Mocan, A.; Nabavi, S.F.; Bishayee, A.; Farooqi, A.A.; Sureda, A.; Nabavi, S.M. Oleanolic Acid Alters Multiple Cell Signaling Pathways: Implication in Cancer Prevention and Therapy. Int. J. Mol. Sci. 2017, 18, 643. [CrossRef]

11. Zhang, R.W. Artemisinin (Qinghaosu), Nobel Prize, anti-malaria, and beyond. Chin. J. Nat. Med. 2016, 14, 1-2. [CrossRef] [PubMed]

12. Weathers, P.J.; Cambra, H.M.; Desrosiers, M.R.; Rassias, D.; Towler, M.J. Chapter 5-Artemisinin the Nobel Molecule: From Plant to Patient. In Studies in Natural Products Chemistry; Attaur, R., Ed.; Elsevier: Amsterdam, The Netherlands, 2017; Volume 52, pp. 193-229.

13. Gong, X.M.; Zhang, Q.; Torossian, A.; Cao, J.P.; Fu, S. Selective radiosensitization of human cervical cancer cells and normal cells by artemisinin through the abrogation of radiation-induced G2 block. Int. J. Gynecol. Cancer 2012, 22, 718-724. [CrossRef] [PubMed]

14. Chou, T.C.; Talalay, P. Quantitative analysis of dose-effect relationships: The combined effects of multiple drugs or enzyme inhibitors. Adv. Enzym. Regul. 1984, 22, 27-55. [CrossRef]

15. UniPortKB. Protein Knowledgebase. Available online: http://www.uniprot.org/uniprot/ (accessed on 28 December 2015). 
16. Shanmugam, M.K.; Lee, J.H.; Chai, E.Z.P.; Kanchi, M.M.; Kar, S.; Arfuso, F.; Dharmarajan, A.; Kumar, A.P.; Ramar, P.S.; Looi, C.Y.; et al. Cancer prevention and therapy through the modulation of transcription factors by bioactive natural compounds. Semin. Cancer Biol. 2016, 40, 35-47. [CrossRef] [PubMed]

17. Firestone, G.L.; Sundar, S.N. Anticancer activities of artemisinin and its bioactive derivatives. Expert Rev. Mol. Med. 2009, 11, e32. [CrossRef]

18. Corte-Rodríguez, M.; Espina, M.; Sierra, L.M.; Blanco, E.; Ames, T.; Montes-Bayón, M.; Sanz-Medel, A. Quantitative evaluation of cellular uptake, DNA incorporation and adduct formation in cisplatin sensitive and resistant cell lines: Comparison of different Pt-containing drugs. Biochem. Pharmacol. 2015, 98, 69-77. [CrossRef]

19. Muenyi, C.S.; Pinhas, A.R.; Fan, T.W.; Brock, G.N.; Helm, C.W.; States, J.C.J.T.S. Sodium arsenite \pm hyperthermia sensitizes p53-expressing human ovarian cancer cells to cisplatin by modulating platinum-DNA damage responses. Toxicol. Sci. 2012, 127, 139-149. [CrossRef]

20. Amable, L.; Smith, S.; Stephan, C.; Shelton, C. New Research Evaluating Cisplatin Uptake in Ovarian Cancer Cells by Single Cell ICP-MS; Perkin Elmer Application Note; Perkin Elmer: Waltham, MA, USA, 2017.

21. Dasari, S.; Tchounwou, P.B. Cisplatin in cancer therapy: Molecular mechanisms of action. Eur. J. Pharmacol. 2014, 740, 364-378. [CrossRef]

22. Wexselblatt, E.; Yavin, E.; Gibson, D. Cellular interactions of platinum drugs. Inorg. Chim. Acta 2012, 393, 75-83. [CrossRef]

23. Song, I.S.; Savaraj, N.; Siddik, Z.H.; Liu, P.; Wei, Y.; Wu, C.J.; Kuo, M.T. Role of human copper transporter Ctr1 in the transport of platinum-based antitumor agents in cisplatin-sensitive and cisplatin-resistant cells. Mol. Cancer Ther. 2004, 3, 1543-1549.

24. Mazumder, M.E.H. Studies on New Tumour Active Palladium Complexes Targeted to Overcome Resistance in Ovarian Cancer. Ph.D. Thesis, University of Sydney, Sydney, Australia, 2013.

25. Gamberi, T.; Massai, L.; Magherini, F.; Landini, I.; Fiaschi, T.; Scaletti, F.; Gabbiani, C.; Bianchi, L.; Bini, L.; Nobili, S.; et al. Proteomic analysis of A2780/S ovarian cancer cell response to the cytotoxic organogold(III) compound Aubipyc. J. Proteom. 2014, 103, 103-120. [CrossRef] [PubMed]

26. Liu, F.T.; Chen, Y.; Yang, Y.J.; Yang, L.; Yu, M.; Zhao, J.; Wu, J.J.; Huang, F.; Liu, W.; Ding, Z.T. Involvement of mortalin/GRP75/mthsp70 in the mitochondrial impairments induced by A53T mutant $\alpha$-synuclein. Brain Res. 2015, 1604, 52-61. [CrossRef] [PubMed]

27. Yang, L.; Li, H.; Jiang, Y.; Zuo, J.; Liu, W. Inhibition of mortalin expression reverses cisplatin resistance and attenuates growth of ovarian cancer cells. Cancer Lett. 2013, 336, 213-221. [CrossRef] [PubMed]

28. Nessa, M.U. Studies on Combinations between Platinum Drugs and Phytochemicals in Ovarian Tumour Models. Ph.D. Thesis, University of Sydney, Sydney, Australia, 2013.

29. Al-Eisawi, Z. Combinations between Platinum Drugs and Bortezomib and Changes in Nature of Administration in Ovarian Tumour Models. Ph.D. Thesis, University of Sydney, Sydney, Australia, 2013.

30. Alamro, A.A.S. Studies on Combination between Tumour Active Compounds in Ovarian Tumour Models. Ph.D. Thesis, University of Sydney, Sydney, Australia, 2015.

31. Li, Y.; Chen, X.; Shi, M.; Wang, H.; Cao, W.; Wang, X.; Li, C.; Feng, W. Proteomic-based identification of Apg-2 as a therapeutic target for chronic myeloid leukemia. Cell. Signal. 2013, 25, 2604-2612. [CrossRef] [PubMed]

32. Kang, J.; Zhao, G.; Lin, T.; Tang, S.; Xu, G.; Hu, S.; Bi, Q.; Guo, C.; Sun, L.; Han, S. A peptide derived from phage display library exhibits anti-tumor activity by targeting GRP78 in gastric cancer multidrug resistance cells. Cancer Lett. 2013, 339, 247-259. [CrossRef] [PubMed]

33. Lee, A.S. GRP78 induction in cancer: Therapeutic and prognostic implications. Cancer Res. 2007, 67, 3496-3499. [CrossRef]

34. Yang, L.; Yang, S.; Liu, J.; Wang, X.; Ji, J.; Cao, Y.; Lu, K.; Wang, J.; Gao, Y. Expression of GRP78 predicts taxane-based therapeutic resistance and recurrence of human gastric cancer. Exp. Mol. Pathol. 2014, 96, 235-241. [CrossRef]

35. Lauber, K.; Brix, N.; Ernst, A.; Hennel, R.; Krombach, J.; Anders, H.; Belka, C. Targeting the heat shock response in combination with radiotherapy: Sensitizing cancer cells to irradiation-induced cell death and heating up their immunogenicity. Cancer Lett. 2015, 368, 209-229. [CrossRef]

36. Partridge, J.R.; Lavery, L.A.; Elnatan, D.; Naber, N.; Cooke, R.; Agard, D.A. A novel N-terminal extension in mitochondrial TRAP1 serves as a thermal regulator of chaperone activity. eLife 2015, 3, e03487. [CrossRef] 
37. Subbarao Sreedhar, A.; Kalmár, É.; Csermely, P.; Shen, Y.F. Hsp90 isoforms: Functions, expression and clinical importance. Fed. Eur. Biochem. Soc. Lett. 2004, 562, 11-15. [CrossRef]

38. Elstrand, M.B.; Stavnes, H.T.; Tropé, C.G.; Davidson, B. Heat shock protein 90 is a putative therapeutic target in patients with recurrent advanced-stage ovarian carcinoma with serous effusions. Hum. Pathol. 2012, 43, 529-535. [CrossRef] [PubMed]

39. Dejeans, N.; Glorieux, C.; Guenin, S.; Beck, R.; Sid, B.; Rousseau, R.; Bisig, B.; Delvenne, P.; Calderon, P.B.; Verrax, J. Overexpression of GRP94 in breast cancer cells resistant to oxidative stress promotes high levels of cancer cell proliferation and migration: Implications for tumor recurrence. Free Radic. Biol. Med. 2012, 52, 993-1002. [CrossRef] [PubMed]

40. Lou, J.; Fatima, N.; Xiao, Z.; Stauffer, S.; Smythers, G.; Greenwald, P.; Ali, I.U. Proteomic profiling identifies cyclooxygenase-2-independent global proteomic changes by celecoxib in colorectal cancer cells. Cancer Epidemiol. Prev. Biomark. 2006, 15, 1598-1606. [CrossRef] [PubMed]

41. Lee, J.; Kim, S.S. Current implications of cyclophilins in human cancers. J. Exp. Clin. Cancer Res. 2010, $29,97$. [CrossRef] [PubMed]

42. Nath, P.R.; Isakov, N. Insights into peptidyl-prolyl cis-trans isomerase structure and function in immunocytes. Immunol. Lett. 2015, 163, 120-131. [CrossRef]

43. Pinto, R.D.; Moreira, A.R.; Pereira, P.J.; dos Santos, N.M. Two thioredoxin-superfamily members from sea bass (Dicentrarchus labrax, L.): Characterization of PDI (PDIA1) and ERp57 (PDIA3). Fish Shellfish Immunol. 2013, 35, 1163-1175. [CrossRef]

44. Kullmann, M.; Kalayda, G.V.; Hellwig, M.; Kotz, S.; Hilger, R.A.; Metzger, S.; Jaehde, U. Assessing the contribution of the two protein disulfide isomerases PDIA1 and PDIA3 to cisplatin resistance. J. Inorg. Biochem. 2015, 153, 247-252. [CrossRef] [PubMed]

45. Caorsi, C.; Niccolai, E.; Capello, M.; Vallone, R.; Chattaragada, M.S.; Alushi, B.; Castiglione, A.; Ciccone, G.; Mautino, A.; Cassoni, P. Protein disulfide isomerase A3-specific Th1 effector cells infiltrate colon cancer tissue of patients with circulating anti-protein disulfide isomerase A3 autoantibodies. Transl. Res. 2016, 171, 17-28. [CrossRef]

46. Andreu, C.I.; Woehlbier, U.; Torres, M.; Hetz, C. Protein disulfide isomerases in neurodegeneration: From disease mechanisms to biomedical applications. Fed. Eur. Biochem. Soc. Lett. 2012, 586, 2826-2834. [CrossRef]

47. Trnková, L.; Ricci, D.; Grillo, C.; Colotti, G.; Altieri, F. Green tea catechins can bind and modify ERp57/PDIA3 activity. Biochim. Biophys. Acta Gen. Subj. 2013, 1830, 2671-2682. [CrossRef]

48. Lee, E.; Lee, D.H. Emerging roles of protein disulfide isomerase in cancer. BMB Rep. 2017, 50, 401. [CrossRef] [PubMed]

49. Leys, C.M.; Nomura, S.; LaFleur, B.J.; Ferrone, S.; Kaminishi, M.; Montgomery, E.; Goldenring, J.R. Expression and prognostic significance of prothymosin- $\alpha$ and ERp57 in human gastric cancer. Surgery 2007, 141, 41-50. [CrossRef] [PubMed]

50. Ren, F.; Wu, H.; Lei, Y.; Zhang, H.; Liu, R.; Zhao, Y.; Chen, X.; Zeng, D.; Tong, A.; Chen, L. Quantitative proteomics identification of phosphoglycerate mutase 1 as a novel therapeutic target in hepatocellular carcinoma. Mol. Cancer 2010, 9, 81. [CrossRef] [PubMed]

51. Zha, X.; Wang, F.; Wang, Y.; He, S.; Jing, Y.; Wu, X.; Zhang, H. Lactate dehydrogenase B is critical for hyperactive mTOR-mediated tumorigenesis. Cancer Res. 2011, 71, 13-18. [CrossRef]

52. Huang, S.K.; Darfler, M.M.; Nicholl, M.B.; You, J.; Bemis, K.G.; Tegeler, T.J.; Wang, M.; Wery, J.P.; Chong, K.K.; Nguyen, L. LC/MS-based quantitative proteomic analysis of paraffin-embedded archival melanomas reveals potential proteomic biomarkers associated with metastasis. PLoS ONE 2009, 4, e4430. [CrossRef]

53. Chang, Y.H.; Wu, C.C.; Chang, K.P.; Yu, J.S.; Chang, Y.C.; Liao, P.C. Cell secretome analysis using hollow fiber culture system leads to the discovery of CLIC1 protein as a novel plasma marker for nasopharyngeal carcinoma. J. Proteome Res. 2009, 8, 5465-5474. [CrossRef]

54. Ding, S.J.; Li, Y.; Shao, X.X.; Zhou, H.; Zeng, R.; Tang, Z.Y.; Xia, Q.C. Proteome analysis of hepatocellular carcinoma cell strains, MHCC97-H and MHCC97-L, with different metastasis potentials. Proteomics 2004, 4, 982-994. [CrossRef]

55. Wang, J.W.; Peng, S.Y.; Li, J.T.; Wang, Y.; Zhang, Z.P.; Cheng, Y.; Cheng, D.Q.; Weng, W.H.; Wu, X.S.; Fei, X.Z. Identification of metastasis-associated proteins involved in gallbladder carcinoma metastasis by proteomic analysis and functional exploration of chloride intracellular channel 1. Cancer Lett. 2009, 281, 71-81. [CrossRef] 
56. Lamb, R.; Harrison, H.; Hulit, J.; Smith, D.L.; Lisanti, M.P.; Sotgia, F. Mitochondria as new therapeutic targets for eradicating cancer stem cells: Quantitative proteomics and functional validation via MCT1/2 inhibition. Oncotarget 2014, 5, 11029-11037. [CrossRef]

57. Onda, M.; Emi, M.; Yoshida, A.; Miyamoto, S.; Akaishi, J.; Asaka, S.; Mizutani, K.; Shimizu, K.; Nagahama, M.; Ito, K. Comprehensive gene expression profiling of anaplastic thyroid cancers with cDNA microarray of 25344 genes. Endocr. Relat. Cancer 2004, 11, 843-854. [CrossRef]

58. Duffy, M.J. Predictive markers in breast and other cancers: A review. Clin. Chem. 2005, 51, 494-503. [CrossRef]

59. Wang, J.; Tai, L.S.; Tzang, C.H.; Fong, W.F.; Guan, X.Y.; Yang, M. 1p31, 7q21 and 18q21 chromosomal aberrations and candidate genes in acquired vinblastine resistance of human cervical carcinoma KB cells. Oncol. Rep. 2008, 19, 1155-1164. [CrossRef] [PubMed]

60. Hofmann, W.K.; de Vos, S.; Elashoff, D.; Gschaidmeier, H.; Hoelzer, D.; Koeffler, H.P.; Ottmann, O.G. Relation between resistance of Philadelphia-chromosome-positive acute lymphoblastic leukaemia to the tyrosine kinase inhibitor STI571 and gene-expression profiles: A gene-expression study. Lancet 2002, 359, 481-486. [CrossRef]

61. Soltysova, A.; Breza, J.; Takacova, M.; Feruszova, J.; Hudecova, S.; Novotna, B.; Rozborilova, E.; Pastorekova, S.; Kadasi, L.; Krizanova, O. Deregulation of energetic metabolism in the clear cell renal cell carcinoma: A multiple pathway analysis based on microarray profiling. Int. J. Oncol. 2015, 47, 287-295. [CrossRef]

62. Yusenko, M.V.; Ruppert, T.; Kovacs, G. Analysis of differentially expressed mitochondrial proteins in chromophobe renal cell carcinomas and renal oncocytomas by 2-D gel electrophoresis. Int. J. Biol. Sci. 2010, 6, 213-224. [CrossRef] [PubMed]

63. Chen, G.; Gharib, T.G.; Huang, C.C.; Thomas, D.G.; Shedden, K.A.; Taylor, J.M.; Kardia, S.L.; Misek, D.E.; Giordano, T.J.; Iannettoni, M.D. Proteomic analysis of lung adenocarcinoma identification of a highly expressed set of proteins in tumors. Clin. Cancer Res. 2002, 8, 2298-2305.

64. Zhang, X.Z.; Xiao, Z.F.; Li, C.; Xiao, Z.Q.; Yang, F.; Li, D.J.; Li, M.Y.; Li, F.; Chen, Z.C. Triosephosphate isomerase and peroxiredoxin 6, two novel serum markers for human lung squamous cell carcinoma. Cancer Sci. 2009, 100, 2396-2401. [CrossRef] [PubMed]

65. Altenberg, B.A.; Greulich, K. Genes of glycolysis are ubiquitously overexpressed in 24 cancer classes. Genomics 2004, 84, 1014-1020. [CrossRef]

66. Di Michele, M.; Marcone, S.; Cicchillitti, L.; Della Corte, A.; Ferlini, C.; Scambia, G.; Donati, M.B.; Rotilio, D. Glycoproteomics of paclitaxel resistance in human epithelial ovarian cancer cell lines: Towards the identification of putative biomarkers. J. Proteom. 2010, 73, 879-898. [CrossRef]

67. Jiang, X.; Chang, H.; Zhou, Y. Expression, purification and preliminary crystallographic studies of human glutamate oxaloacetate transaminase 1 (GOT1). Protein Expr. Purif. 2015, 113, 102-106. [CrossRef]

68. Yu, M.; Zhou, Q.; Zhou, Y.; Fu, Z.; Tan, L.; Ye, X.; Zeng, B.; Gao, W.; Zhou, J.; Liu, Y. Metabolic phenotypes in pancreatic cancer. PLoS ONE 2015, 10, e0115153. [CrossRef] [PubMed]

69. Chakrabarti, G. Mutant KRAS associated malic enzyme 1 expression is a predictive marker for radiation therapy response in non-small cell lung cancer. Radiat. Oncol. 2015, 10, 145. [CrossRef] [PubMed]

70. Takács-Vellai, K. The metastasis suppressor Nm23 as a modulator of Ras/ERK signaling. J. Mol. Signal. 2014, 9, 4. [CrossRef] [PubMed]

71. Jin, L.; Liu, G.; Zhang, C.H.; Lu, C.H.; Xiong, S.; Zhang, M.Y.; Liu, Q.Y.; Ge, F.; He, Q.Y.; Kitazato, K.; et al. Nm23-H1 regulates the proliferation and differentiation of the human chronic myeloid leukemia K562 cell line: A functional proteomics study. Life Sci. 2009, 84, 458-467. [CrossRef] [PubMed]

72. Yi, S.; Guangqi, H.; Guoli, H. The association of the expression of MTA1, nm23H1 with the invasion, metastasis of ovarian carcinoma. Chin. Med. Sci. J. 2003, 18, 87-92. [PubMed]

73. Liu, S.; Sun, Y.; Tian, D.; He, Y.; Zeng, L.; He, Y.; Ling, C.; Sun, S. Downregulated NM23-H1 expression is associated with intracranial invasion of nasopharyngeal carcinoma. Br. J. Cancer 2008, 98, 363-369. [CrossRef] [PubMed]

74. Yang, R.F.; Sun, L.H.; Zhang, R.; Zhang, Y.; Luo, Y.X.; Zheng, W.; Zhang, Z.Q.; Chen, H.Z.; Liu, D.P. Suppression of Mic60 compromises mitochondrial transcription and oxidative phosphorylation. Sci. Rep. 2015, 5, 7990. [CrossRef]

75. Liu, Z.; Marquez, M.; Nilsson, S.; Holmberg, A.R. Comparison of protein expression in two prostate cancer cell-lines, LNCaP and DU145, after treatment with somatostatin. Oncol. Rep. 2009, 22, 1451-1458. [CrossRef] 
76. Wong, T.S.; Liu, X.B.; Chung-Wai Ho, A.; Po-Wing Yuen, A.; Wai-Man Ng, R.; Ignace Wei, W. Identification of pyruvate kinase type M2 as potential oncoprotein in squamous cell carcinoma of tongue through microRNA profiling. Int. J. Cancer 2008, 123, 251-257. [CrossRef]

77. He, Y.; Wang, Y.; Liu, H.; Xu, X.; He, S.; Tang, J.; Huang, Y.; Miao, X.; Wu, Y.; Wang, Q. Pyruvate kinase isoform M2 (PKM2) participates in multiple myeloma cell proliferation, adhesion and chemoresistance. Leuk. Res. 2015, 39, 1428-1436. [CrossRef]

78. Sun, Q.; Chen, X.; Ma, J.; Peng, H.; Wang, F.; Zha, X.; Wang, Y.; Jing, Y.; Yang, H.; Chen, R. Mammalian target of rapamycin up-regulation of pyruvate kinase isoenzyme type M2 is critical for aerobic glycolysis and tumor growth. Proc. Natl. Acad. Sci. USA 2011, 108, 4129-4134. [CrossRef] [PubMed]

79. Li, X.H.; Li, C.; Xiao, Z.Q. Proteomics for identifying mechanisms and biomarkers of drug resistance in cancer. J. Proteom. 2011, 74, 2642-2649. [CrossRef] [PubMed]

80. Martinez-Balibrea, E.; Plasencia, C.; Ginés, A.; Martinez-Cardús, A.; Musulén, E.; Aguilera, R.; Manzano, J.L.; Neamati, N.; Abad, A. A proteomic approach links decreased pyruvate kinase M2 expression to oxaliplatin resistance in patients with colorectal cancer and in human cell lines. Mol. Cancer Ther. 2009, 8, 771-778. [CrossRef]

81. Desai, S.; Ding, M.; Wang, B.; Lu, Z.; Zhao, Q.; Shaw, K.; Yung, W.; Weinstein, J.N.; Tan, M.; Yao, J. Tissue-specific isoform switch and DNA hypomethylation of the pyruvate kinase PKM gene in human cancers. Oncotarget 2014, 5, 8202-8210. [CrossRef] [PubMed]

82. Baek, J.Y.; Jun, D.Y.; Dennis, T.; Kim, Y.H. Characterization of human phosphoserine aminotransferase involved in the phosphorylated pathway of L-serine biosynthesis. Biochem. J. 2003, 373, 191-200. [CrossRef] [PubMed]

83. Vié, N.; Copois, V.; Bascoul-Mollevi, C.; Denis, V.; Bec, N.; Robert, B.; Fraslon, C.; Conseiller, E.; Molina, F.; Larroque, C. Overexpression of phosphoserine aminotransferase PSAT1 stimulates cell growth and increases chemoresistance of colon cancer cells. Mol. Cancer 2008, 7, 14. [CrossRef]

84. Toyama, A.; Suzuki, A.; Shimada, T.; Aoki, C.; Aoki, Y.; Umino, Y.; Nakamura, Y.; Aoki, D.; Sato, T.A. Proteomic characterization of ovarian cancers identifying annexin-A4, phosphoserine aminotransferase, cellular retinoic acid-binding protein 2, and serpin B5 as histology-specific biomarkers. Cancer Sci. 2012, 103, 747-755. [CrossRef]

85. Arif, T.; Krelin, Y.; Shoshan-Barmatz, V. Reducing VDAC1 expression induces a non-apoptotic role for pro-apoptotic proteins in cancer cell differentiation. Biochim. Biophys. Acta Bioenerg. 2016, 1857, 1228-1242. [CrossRef]

86. Shoshan-Barmatz, V.; Ben-Hail, D.; Admoni, L.; Krelin, Y.; Tripathi, S.S. The mitochondrial voltage-dependent anion channel 1 in tumor cells. Biochim. Biophys. Acta Biomembr. 2015, 1848, 2547-2575. [CrossRef]

87. Capello, M.; Ferri-Borgogno, S.; Cappello, P.; Novelli, F. Alpha-Enolase: A promising therapeutic and diagnostic tumor target. Fed. Eur. Biochem. Soc. J. 2011, 278, 1064-1074. [CrossRef]

88. Capello, M.; Caorsi, C.; Bogantes Hernandez, P.J.; Dametto, E.; Bertinetto, F.E.; Magistroni, P.; Rendine, S.; Amoroso, A.; Novelli, F. Phosphorylated alpha-enolase induces autoantibodies in HLA-DR8 pancreatic cancer patients and triggers HLA-DR8 restricted T-cell activation. Immunol. Lett. 2015, 167, 11-16. [CrossRef] [PubMed]

89. Satelli, A.; Li, S. Vimentin in cancer and its potential as a molecular target for cancer therapy. Cell. Mol. Life Sci. 2011, 68, 3033-3046. [CrossRef] [PubMed]

90. Kidd, M.E.; Shumaker, D.K.; Ridge, K.M. The role of vimentin intermediate filaments in the progression of lung cancer. Am. J. Respir. Cell Mol. Biol. 2014, 50, 1-6. [CrossRef] [PubMed]

91. Fontana, S.; Alessandro, R.; Barranca, M.; Giordano, M.; Corrado, C.; Zanella-Cleon, I.; Becchi, M.; Kohn, E.C.; De Leo, G. Comparative proteome profiling and functional analysis of chronic myelogenous leukemia cell lines. J. Proteome Res. 2007, 6, 4330-4342. [CrossRef] [PubMed]

92. Chiang, W.L.; Chu, S.C.; Yang, S.S.; Li, M.C.; Lai, J.C.; Yang, S.F.; Chiou, H.L.; Hsieh, Y.S. The aberrant expression of cytosolic carbonic anhydrase and its clinical significance in human non-small cell lung cancer. Cancer Lett. 2002, 188, 199-205. [CrossRef]

93. Kuo, W.H.; Chiang, W.L.; Yang, S.F.; Yeh, K.T.; Yeh, C.M.; Hsieh, Y.S.; Chu, S.C. The differential expression of cytosolic carbonic anhydrase in human hepatocellular carcinoma. Life Sci. 2003, 73, 2211-2223. [CrossRef]

94. Goldmann, W.H.; Auernheimer, V.; Thievessen, I.; Fabry, B. Vinculin, cell mechanics and tumour cell invasion. Cell Biol. Int. 2013, 37, 397-405. [CrossRef] [PubMed] 
95. Cao, X.X.; Xu, J.D.; Liu, X.L.; Xu, J.W.; Wang, W.J.; Li, Q.Q.; Chen, Q.; Xu, Z.D.; Liu, X.P. RACK1: A superior independent predictor for poor clinical outcome in breast cancer. Int. J. Cancer 2010, 127, 1172-1179. [CrossRef]

96. Kuramitsu, Y.; Wang, Y.; Okada, F.; Baron, B.; Tokuda, K.; Kitagawa, T.; Akada, J.; Nakamura, K. Malignant progressive tumor cell clone exhibits significant up-regulation of cofilin-2 and 27-kDa modified form of cofilin-1 compared to regressive clone. Anticancer Res. 2013, 33, 3661-3665.

97. Yan, H.; Yang, K.; Xiao, H.; Zou, Y.J.; Zhang, W.B.; Liu, H.Y. Over-expression of cofilin-1 and phosphoglycerate kinase 1 in astrocytomas involved in pathogenesis of radioresistance. CNS Neurosci. Ther. 2012, 18, 729-736. [CrossRef]

98. Tariq, M.; Ito, A.; Ishfaq, M.; Bradshaw, E.; Yoshida, M. Eukaryotic translation initiation factor 5A (eIF5A) is essential for HIF-1 $\alpha$ activation in hypoxia. Biochem. Biophys. Res. Commun. 2016, 470, 417-424. [CrossRef] [PubMed]

99. Shi, S.; Deng, Y.Z.; Zhao, J.S.; Ji, X.D.; Shi, J.; Feng, Y.X.; Li, G.; Li, J.J.; Zhu, D.; Koeffler, H.P. RACK1 promotes non-small-cell lung cancer tumorigenicity through activating sonic hedgehog signaling pathway. J. Biol. Chem. 2012, 287, 7845-7858. [CrossRef] [PubMed]

100. Mathews, M.B.; Hershey, J.W. The translation factor eIF5A and human cancer. Biochim. Biophys. Acta Gene Regul. Mech. 2015, 1849, 836-844. [CrossRef] [PubMed]

101. Scuoppo, C.; Miething, C.; Lindqvist, L.; Reyes, J.; Ruse, C.; Appelmann, I.; Yoon, S.; Krasnitz, A.; Teruya-Feldstein, J.; Pappin, D. A tumour suppressor network relying on the polyamine-hypusine axis. Nature 2012, 487, 244-248. [CrossRef] [PubMed]

102. Nakamura, J.; Aoyagi, S.; Nanchi, I.; Nakatsuka, S.I.; Hirata, E.; Shibata, S.; Fukuda, M.; Yamamoto, Y.; Fukuda, I.; Tatsumi, N. Overexpression of eukaryotic elongation factor eEF2 in gastrointestinal cancers and its involvement in G2/M progression in the cell cycle. Int. J. Oncol. 2009, 34, 1181.

103. Hamrita, B.; Nasr, H.B.; Hammann, P.; Kuhn, L.; Guillier, C.L.; Chaieb, A.; Khairi, H.; Chahed, K. An elongation factor-like protein (EF-Tu) elicits a humoral response in infiltrating ductal breast carcinomas: An immunoproteomics investigation. Clin. Biochem. 2011, 44, 1097-1104. [CrossRef]

104. Tomaino, B.; Cappello, P.; Capello, M.; Fredolini, C.; Ponzetto, A.; Novarino, A.; Ciuffreda, L.; Bertetto, O.; De Angelis, C.; Gaia, E. Autoantibody signature in human ductal pancreatic adenocarcinoma. J. Proteome Res. 2007, 6, 4025-4031. [CrossRef]

105. Srisomsap, C.; Sawangareetrakul, P.; Subhasitanont, P.; Panichakul, T.; Keeratichamroen, S.; Lirdprapamongkol, K.; Chokchaichamnankit, D.; Sirisinha, S.; Svasti, J. Proteomic analysis of cholangiocarcinoma cell line. Proteomics 2004, 4, 1135-1144. [CrossRef] [PubMed]

106. Sen, S.; Ateeq, B.; Sharma, H.; Datta, P.; Gupta, S.D.; Bal, S.; Kumar, A.; Singh, N. Molecular profiling of genes in squamous cell lung carcinoma in Asian Indians. Life Sci. 2008, 82, 772-779. [CrossRef]

107. Ryningen, A.; Ersvær, E.; Øyan, A.M.; Kalland, K.H.; Vintermyr, O.K.; Gjertsen, B.T.; Bruserud, Ø. Stress-induced in vitro apoptosis of native human acute myelogenous leukemia (AML) cells shows a wide variation between patients and is associated with low BCL-2: Bax ratio and low levels of heat shock protein 70 and 90. Leuk. Res. 2006, 30, 1531-1540. [CrossRef]

108. Ogawa, K.; Utsunomiya, T.; Mimori, K.; Tanaka, Y.; Tanaka, F.; Inoue, H.; Murayama, S.; Mori, M. Clinical significance of elongation factor- 1 delta mRNA expression in oesophageal carcinoma. Br. J. Cancer 2004, 91, 282-286. [CrossRef] [PubMed]

109. Chen, R.; Eugene, C.Y.; Donohoe, S.; Pan, S.; Eng, J.; Cooke, K.; Crispin, D.A.; Lane, Z.; Goodlett, D.R.; Bronner, M.P. Pancreatic cancer proteome: The proteins that underlie invasion, metastasis, and immunologic escape. Gastroenterology 2005, 129, 1187-1197. [CrossRef] [PubMed]

110. Zhong, D.; Zhang, J.; Yang, S.; Soh, U.J.; Buschdorf, J.P.; Zhou, Y.T.; Yang, D.; Low, B.C. The SAM domain of the RhoGAP DLC1 binds EF1A1 to regulate cell migration. J. Cell Sci. 2009, 122, 414-424. [CrossRef] [PubMed]

111. Carpenter, B.; MacKay, C.; Alnabulsi, A.; MacKay, M.; Telfer, C.; Melvin, W.T.; Murray, G.I. The roles of heterogeneous nuclear ribonucleoproteins in tumour development and progression. Biochim. Biophys. Acta Rev. Cancer 2006, 1765, 85-100. [CrossRef] [PubMed]

112. Jean-Philippe, J.; Paz, S.; Caputi, M. hnRNP A1: The Swiss army knife of gene expression. Int. J. Mol. Sci. 2013, 14, 18999-19024. [CrossRef] [PubMed] 
113. Pino, I.; Pio, R.; Toledo, G.; Zabalegui, N.; Vicent, S.; Rey, N.; Lozano, M.D.; Torre, W.; Garcia-Foncillas, J.; Montuenga, L.M. Altered patterns of expression of members of the heterogeneous nuclear ribonucleoprotein (hnRNP) family in lung cancer. Lung Cancer 2003, 41, 131-143. [CrossRef]

114. Chen, Z.Y.; Cai, L.; Zhu, J.; Chen, M.; Chen, J.; Li, Z.H.; Liu, X.D.; Wang, S.G.; Bie, P.; Jiang, P. Fyn requires HnRNPA2B1 and Sam68 to synergistically regulate apoptosis in pancreatic cancer. Carcinogenesis 2011, 32, 1419-1426. [CrossRef]

115. Yan-Sanders, Y.; Hammons, G.J.; Lyn-Cook, B.D. Increased expression of heterogeneous nuclear ribonucleoprotein A2/B1 (hnRNP) in pancreatic tissue from smokers and pancreatic tumor cells. Cancer Lett. 2002, 183, 215-220. [CrossRef]

116. Zhang, D.; Tai, L.K.; Wong, L.L.; Chiu, L.L.; Sethi, S.K.; Koay, E.S. Proteomic study reveals that proteins involved in metabolic and detoxification pathways are highly expressed in her-2/neu-positive breast cancer. Mol. Cell. Proteom. 2005, 4, 1686-1696. [CrossRef]

117. Duan, Z.; Lamendola, D.; Yusuf, R.; Penson, R.; Preffer, F.; Seiden, M. Overexpression of human phosphoglycerate kinase 1 (PGK1) induces a multidrug resistance phenotype. Anticancer Res. 2001, 22, 1933-1941.

118. Hwang, T.L.; Liang, Y.; Chien, K.Y.; Yu, J.S. Overexpression and elevated serum levels of phosphoglycerate kinase 1 in pancreatic ductal adenocarcinoma. Proteomics 2006, 6, 2259-2272. [CrossRef] [PubMed]

119. Unwin, R.D.; Craven, R.A.; Harnden, P.; Hanrahan, S.; Totty, N.; Knowles, M.; Eardley, I.; Selby, P.J.; Banks, R.E. Proteomic changes in renal cancer and co-ordinate demonstration of both the glycolytic and mitochondrial aspects of the Warburg effect. Proteomics 2003, 3, 1620-1632. [CrossRef] [PubMed]

120. Ren, P.; Ye, H.; Dai, L.; Liu, M.; Liu, X.; Chai, Y.; Shao, Q.; Li, Y.; Lei, N.; Peng, B. Peroxiredoxin 1 is a tumor-associated antigen in esophageal squamous cell carcinoma. Oncol. Rep. 2013, 30, 2297-2303. [CrossRef] [PubMed]

121. Anwar, S.; Yanai, T.; Sakai, H. Overexpression of Peroxiredoxin 6 Protects Neoplastic Cells against Apoptosis in Canine Haemangiosarcoma. J. Comp. Pathol. 2016, 155, 29-39. [CrossRef]

122. Yun, H.M.; Park, K.R.; Lee, H.P.; Lee, D.H.; Jo, M.; Shin, D.H.; Yoon, D.Y.; Han, S.B.; Hong, J.T. PRDX6 promotes lung tumor progression via its GPx and iPLA2 activities. Free Radic. Biol. Med. 2014, 69, 367-376. [CrossRef]

123. Sherbet, G.V.; Cajone, F. Stathmin in cell proliferation and cancer progression. Cancer Genom. Proteom. 2005, 2, 227-238.

124. Fang, L.; Min, L.; Lin, Y.; Ping, G.; Rui, W.; Ying, Z.; Xi, W.; Ting, H.; Li, L.; Ke, D. Downregulation of stathmin expression is mediated directly by Egr1 and associated with p53 activity in lung cancer cell line A549. Cell. Signal. 2010, 22, 166-173. [CrossRef]

125. Kim, D.W.; Kim, J.Y.; Moon, J.H.; Kim, K.B.; Kim, T.S.; Hong, S.J.; Cheon, Y.P.; Pak, J.H.; Seo, S.B. Transcriptional induction of minichromosome maintenance protein $7(\mathrm{Mcm} 7)$ in human cholangiocarcinoma cells treated with Clonorchis sinensis excretory-secretory products. Mol. Biochem. Parasitol. 2010, 173, 10-16. [CrossRef]

126. Luo, J.H. Oncogenic activity of MCM7 transforming cluster. World J. Clin. Oncol. 2011, 2, 120. [CrossRef]

127. Milton, R.H.; Abeti, R.; Averaimo, S.; DeBiasi, S.; Vitellaro, L.; Jiang, L.; Curmi, P.M.; Breit, S.N.; Duchen, M.R.; Mazzanti, M. CLIC1 function is required for $\beta$-amyloid-induced generation of reactive oxygen species by microglia. J. Neurosci. 2008, 28, 11488-11499. [CrossRef]

128. Barrès, V.; Ouellet, V.; Lafontaine, J.; Tonin, P.N.; Provencher, D.M.; Mes-Masson, A.M. An essential role for Ran GTPase in epithelial ovarian cancer cell survival. Mol. Cancer 2010, 9, 272. [CrossRef]

129. Caputo, E.; Wang, E.; Valentino, A.; Crispi, S.; De Giorgi, V.; Fico, A.; Ficili, B.; Capone, M.; Anniciello, A.; Cavalcanti, E. Ran signaling in melanoma: Implications for the development of alternative therapeutic strategies. Cancer Lett. 2015, 357, 286-296. [CrossRef] [PubMed]

130. Zhao, J.; Meyerkord, C.L.; Du, Y.; Khuri, F.R.; Fu, H. 14-3-3 proteins as potential therapeutic targets. Semin. Cell Dev. Biol. 2011, 22, 705-712. [CrossRef] [PubMed]

131. Klemm, C.; Dommisch, H.; Göke, F.; Kreppel, M.; Jepsen, S.; Rolf, F.; Dommisch, K.; Perner, S.; Standop, J. Expression profiles for 14-3-3 zeta and CCL20 in pancreatic cancer and chronic pancreatitis. Pathol. Res. Pract. 2014, 210, 335-341. [CrossRef] [PubMed]

132. Chen, M.; Huang, H.; He, H.; Ying, W.; Liu, X.; Dai, Z.; Yin, J.; Mao, N.; Qian, X.; Pan, L. Quantitative proteomic analysis of mitochondria from human ovarian cancer cells and their paclitaxel-resistant sublines. Cancer Sci. 2015, 106, 1075-1083. [CrossRef] 


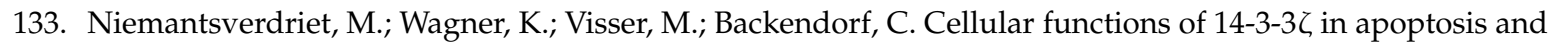
cell adhesion emphasize its oncogenic character. Oncogene 2008, 27, 1315-1319. [CrossRef]

134. Livinskaya, V.A.; Barlev, N.A.; Nikiforov, A.A. Immunoaffinity purification of the functional $20 \mathrm{~S}$ proteasome from human cells via transient overexpression of specific proteasome subunits. Protein Expr. Purif. 2014, 97, 37-43. [CrossRef]

135. Moghanibashi, M.; Jazii, F.R.; Soheili, Z.S.; Zare, M.; Karkhane, A.; Parivar, K.; Mohamadynejad, P. Proteomics of a new esophageal cancer cell line established from Persian patient. Gene 2012, 500, 124-133. [CrossRef]

136. Hu, X.T.; Chen, W.; Wang, D.; Shi, Q.L.; Zhang, F.B.; Liao, Y.Q.; Jin, M.; He, C. The proteasome subunit PSMA7 located on the 20q13 amplicon is overexpressed and associated with liver metastasis in colorectal cancer. Oncol. Rep. 2008, 19, 441-446. [CrossRef]

137. Langdon, S.P. Cancer Cell Culture: Methods and Protocols. In Methods in Molecular Biology; Illustrated Edition; Langdon, S.P., Ed.; Humana Press Inc.: Totowa, NJ, USA, 2004; pp. 133-138.

138. Holford, J.; Beale, P.; Boxall, F.; Sharp, S.; Kelland, L. Mechanisms of drug resistance to the platinum complex ZD0473 in ovarian cancer cell lines. Eur. J. Cancer 2000, 36, 1984-1990. [CrossRef]

139. Mosmann, T. Rapid colorimetric assay for cellular growth and survival: Application to proliferation and cytotoxicity assays. J. Immunol. Methods 1983, 65, 55-63. [CrossRef]

140. Chou, T.C. Theoretical basis, experimental design, and computerized simulation of synergism and antagonism in drug combination studies. Pharmacol. Rev. 2006, 58, 621-681. [CrossRef]

141. GENOMED. Purifying gDNA from Mammalian Cells. Available online: http://manualzz.com/doc/7146492/ cst-genomic-dna-purification-kits----tissues (accessed on 2 June 2015).

142. Holford, J.; Sharp, S.; Murrer, B.; Abrams, M.; Kelland, L. In vitro circumvention of cisplatin resistance by the novel sterically hindered platinum complex AMD473. Br. J. Cancer 1998, 77, 366. [CrossRef] [PubMed]

143. Maloney, A.; Clarke, P.A.; Naaby-Hansen, S.; Stein, R.; Koopman, J.O.; Akpan, A.; Yang, A.; Zvelebil, M.; Cramer, R.; Stimson, L. Gene and protein expression profiling of human ovarian cancer cells treated with the heat shock protein 90 inhibitor 17-allylamino-17-demethoxygeldanamycin. Cancer Res. 2007, 67, 3239-3253. [CrossRef] [PubMed]

144. Wood, R. Bio-Rad Protein Assay. Available online: http://www.bio-rad.com/webroot/web/pdf/lsr/literature/ LIT33.pdf (accessed on 2 June 2015).

145. Bradford, M.M. A rapid and sensitive method for the quantitation of microgram quantities of protein utilizing the principle of protein-dye binding. Anal. Biochem. 1976, 72, 248-254. [CrossRef]

146. Bio-Rad. ReadyPrep 2-D Starter Kit. Available online: http://www.bio-rad.com/webroot/web/pdf/lsr/ literature/4110009A.pdf (accessed on 2 June 2015).

147. Bio-Rad. 2-D Electrophoresis Workflow How-to Guide. Available online: http://www.bio-rad.com/webroot/ web/pdf/lsr/literature/Bulletin_2651.pdf (accessed on 2 June 2015).

148. Bio-Rad. Criterion Dodeca Cell. Available online: http://www.bio-rad.com/webroot/web/pdf/lsr/literature/ 4006197a.pdf (accessed on 2 June 2015).

149. Bio-Rad. ChemiDoc XRS+Systems with Image Lab Software User Guid. Available online: http://www.biorad.com/webroot/web/pdf/lsr/literature/10017218.pdf (accessed on 2 June 2015).

150. Bio-Rad. Melanie 3 User Manual. Available online: https://www.bio-rad.com/webroot/web/pdf/lsr/literature/ 4000151A.pdf (accessed on 2 June 2015).

151. Winnik, W.M.; DeKroon, R.M.; Jeong, J.S.; Mocanu, M.; Robinette, J.B.; Osorio, C.; Dicheva, N.N.; Hamlett, E.; Alzate, O. Analysis of proteins using DIGE and MALDI mass spectrometry. In Difference Gel Electrophoresis (DIGE) Methods and Protocols; Humana Press: Tortowa, NJ, USA, 2012; Volume 854, pp. 47-66.

Publisher's Note: MDPI stays neutral with regard to jurisdictional claims in published maps and institutional affiliations.

(C) 2020 by the authors. Licensee MDPI, Basel, Switzerland. This article is an open access article distributed under the terms and conditions of the Creative Commons Attribution (CC BY) license (http://creativecommons.org/licenses/by/4.0/). 